\title{
Association of MicroRNA Biogenesis Genes Polymorphisms with Ischemic Stroke Susceptibility and Post-Stroke Mortality
}

\author{
Jung Oh Kim, ${ }^{\mathrm{a},{ }^{*}}$ Jinkun Bae, ${ }^{\mathrm{b},}{ }^{*}$ Jinkwon Kim, ${ }^{\mathrm{c}}$ Seung Hun Oh, ${ }^{\mathrm{c}}$ Hui Jeong An, ${ }^{\mathrm{a}}$ In Bo Han, ${ }^{\mathrm{d}}$ Doyeun Oh, \\ Ok Joon Kim, ${ }^{\mathrm{c}}$ Nam Keun Kim ${ }^{\mathrm{a}}$ \\ aDepartment of Biomedical Science, CHA University College of Life Science, Seongnam, Korea \\ ${ }^{b}$ Department of Emergency Medicine, CHA Bundang Medical Center, CHA University, Seongnam, Korea \\ 'Department of Neurology, CHA Bundang Medical Center, CHA University, Seongnam, Korea \\ dDepartment of Neurosurgery, CHA Bundang Medical Center, CHA University, Seongnam, Korea \\ 'Department of Internal Medicine, CHA University, Seongnam, Korea
}

Background and Purpose MicroRNA (miRNA) expression has been examined in multiple conditions, including various cancers, neurological diseases, and cerebrovascular diseases, particularly stroke. Existing evidence indicates that miRNA biosynthesis and function play crucial roles in ischemic stroke physiology and pathology. In this study, we selected six known polymorphisms in miRNAbiogenesis genes; DICER rs13078A>T, rs3742330A>G; DROSHA rs10719T>C, rs6877842G $>C$; Ran GTPase (RAM) rs14035C >T; exportin 5 (XP05) rs11077A>C.

Methods We analyzed the associations between these polymorphisms and disease status and clinical factors in 585 ischemic stroke patients and 403 controls. Genotyping was performed with the polymerase chain reaction-restriction fragment length polymorphism method.

Results The DICER rs3742330A>G (AA vs. AG+GG: adjusted odds ratio [AOR], 1.360; 95\% confidence interval $[\mathrm{Cl}], 1.024$ to $1.807 ; P=0.034$ ) and $D R O S H A$ rs $10719 T>C$ polymorphisms ( $\Pi$ vs. CC: $A O R, 2.038 ; 95 \% \mathrm{Cl}, 1.113$ to $3.730 ; P=0.021$ ) were associated with ischemic stroke prevalence. During a mean follow-up of $4.80 \pm 2.11$ years, $99(5.91 \%)$ of the stroke patients died. In multivariate Cox proportional hazard regression models, a significant association was found between RAN rs 14035 and survival of large artery disease patients with ischemic stroke (CC vs. Tा: adjusted hazard ratio, 5.978; $P=0.015$ ).

Conclusions An association was identified between the DICER and DROSHA polymorphisms and ischemic stroke. Specifically, polymorphisms (rs3742330 and rs10719) were more common in stroke patients, suggesting that they may be associated with an increased risk of ischemic stroke.
Correspondence: Nam Keun Kim Department of Biomedical Science, CHA University College of Life Science, 335 Pangyo-ro, Bundang-gu,

Seongnam 13488, Korea

Tel: +82-31-881-7137

Fax: +82-31-881-7249

E-mail:nkkim@cha.ac.kr

Co-correspondence: Ok Joon Kim Department of Neurology, CHA Bundang Medical Center, CHA University, 59 Yatap-ro, Bundang-gu, Seongnam 13496, Korea

Tel: +82-31-780-5481

Fax: +82-31-881-7249

E-mail: okjun77@cha.ac.kr

Received: November 6, 2017

Revised: December 30, 2017

Accepted: January 19, 2018

*These authors contributed equally to the manuscript as first author.

Keywords Polymorphism, genetic; Stroke; MicroRNA biogenesis genes; Mortality

Copyright (C) 2018 Korean Stroke Society

This is an Open Access article distributed under the terms of the Creative Commons Attribution Non-Commercial License (http://creativecommons.org/licenses/by-nc/4.0/) which permits unrestricted non-commercial use, distribution, and reproduction in any medium, provided the original work is properly cited. 


\section{Introduction}

Stroke is regarded as a complex, multifactorial, polygenic disease arising from a wide number of gene-gene and gene-environment interactions. ${ }^{1,2}$ Multiple factors including hypertension, diabetes mellitus, smoking, hyperlipidemia, and hyperhomocysteinemia are associated with a higher risk of stroke. ${ }^{3.4}$ Hyperhomocysteinemia, in particular, has been demonstrated to be an independent risk factor for ischemic stroke in several studies involving different ethnic groups. ${ }^{5,6}$

MicroRNAs (miRNAs) are a class of endogenous, small, noncoding RNAs that pair with sites in 3'-untranslated regions (3'-UTRs) in mRNAs to downregulate their expression. ${ }^{7-9}$ Previous studies have suggested that gene expression may be regulated by a small number of miRNAs. ${ }^{10-13}$ To date, miRNA expression has been examined in patients with tumors, ${ }^{12,14,15}$ Alzheimer's disease, ${ }^{16}$ Parkinson's disease, ${ }^{17}$ schizophrenia, ${ }^{18}$ and stroke. ${ }^{19-21}$ The evidence gathered to date indicates that miRNA biosynthesis plays crucial, physiological, and pathological roles. ${ }^{22-24}$ Biosynthesis of miRNAs involves several miRNA biogenesis genes and occurs in multiple steps.? RNA polymerase II produces large primary miRNA transcripts (about 500 to 3,000 nucleotides) in the nucleus. The transcripts are processed by a multiprotein complex that includes DROSHA to form precursor miRNA (pre-miRNA) hairpins (about 60 to 100 nucleotides). After pre-miRNA has been exported to the cytoplasm by Ran GTPase (RAM) and exportin 5 (XPO5), it is further processed by DICER1, a polymerase II enzyme. Subsequently, the double-stranded miRNA duplex unwinds, forming an 18- to 24-nucleotide single-stranded, mature miRNA. ${ }^{725-27}$

The present study tested the hypothesis that there is an association between miRNA biogenesis gene polymorphism and ischemic stroke risk. The objective was to investigate associations between six known miRNA biogenesis gene polymorphisms (DICER 3'-UTR rs13078A>T, DICER 3'-UTR rs3742330A>G, DROSHA 3'-UTR rs10719T>C, DROSHA 3'-UTR rs6877842G $>C$, RAN 3'-UTR rs $14035 \mathrm{C}>\mathrm{T}$, and XP05 3'-UTR rs11077A $>C$ ) and ischemic stroke and its risk factors.

\section{Methods}

\section{Ethics statement}

All study protocols were reviewed and approved by the Institutional Review Board of CHA Bundang Medical Center and followed the recommendations of the Declaration of Helsinki. Study subjects were recruited from the South Korean provinces of Seoul and Gyeonggi-do between 2000 and 2008. The Institutional Review Board of CHA Bundang Medical Center approved this genetic study in June 2000 (IRB No. 2013-09-073) and informed consent was obtained from study participants.

\section{Study population}

The Department of Neurology at CHA Bundang Medical Center, CHA University, referred 585 consecutive patients with ischemic stroke. Ischemic stroke was defined as a stroke (a clinical syndrome characterized by rapidly developing clinical symptoms and signs of focal or global loss of brain function) with evidence of cerebral infarction in clinically relevant areas of the brain according to magnetic resonance imaging (MRI) scan finding. Based on clinical manifestations and neuroimaging data, two neurologists classified all ischemic strokes into four causative subtypes using the Trial of Org 10172 in Acute Stroke Treatment (TOAST) criteria, as follows: (1) large artery disease $(L A D)$, characterized by an infarction lesion $\geq 15 \mathrm{~mm}$ in diameter documented by MRI, and significant $(>50 \%)$ stenosis of a major brain artery or a branch cortical artery documented by cerebral angiography with symptoms associated with that arterial territory; (2) small vessel disease (SVD), characterized by an infarction lesion $<15$ and $\geq 5 \mathrm{~mm}$ in diameter documented using MRI, and classic lacunar syndrome without evidence of cerebral cortical dysfunction or potentially detectable cardiac sources for embolism; (3) cardioembolism (CE) or arterial occlusions presumably due to an embolus arising in the heart, as detected by cardiac evaluation; and (4) undetermined pathogenesis, in which the cause of stroke could not be determined with any degree of confidence or involved $>2$ causes. Single and multiple ( $\geq 2$ lesions) SVD cases were distinguished via brain MRI scans. The sizes and sites of cerebral infarctions were documented using MRI only. We selected 403 control subjects that were matched for sex ratio and age (within 5 years) in accordance with the patient group (Table 1). Controls were drawn from subjects visiting our hospitals during the same period for health examinations, including biochemical testing, electrocardiograms, and brain MRIs. Control subjects did not have a recent history of cerebrovascular disease or myocardial infarction. Exclusion criteria were the same as those used for the case group, as mentioned previously.

\section{Genotyping}

DNA was extracted from leukocytes using a G-DEX II Genomic DNA Extraction kit (Intron Biotechnology, Seongnam, Korea) according to the manufacturer's instructions. The six best-studied single nucleotide polymorphisms (SNPs) in the miRNA biogenesis genes were determined through a documentary search that included 3'-UTR SNPs (DICER rs13078A >T, rs3742330A >G, DROSHA rs10719T $>$ C, rs6877842G $>C$, RAN rs $14035 \mathrm{C}>\mathrm{T}$, and $X P 05$ rs $11077 \mathrm{~A}>\mathrm{C}$ ). The miRNA biogenesis gene polymorphisms 
Table 1. Baseline characteristics of ischemic stroke cases and controls

\begin{tabular}{|c|c|c|c|}
\hline Characteristic & Cases $(n=585)$ & Controls $(n=403)$ & $P^{*}$ \\
\hline Male sex & $243(41.5)$ & $168(41.7)$ & 1.000 \\
\hline Age (yr) & $62.72 \pm 10.91$ & $62.79 \pm 10.61$ & 0.249 \\
\hline Smokers & $206(35.2)$ & $133(33.0)$ & 0.654 \\
\hline Hypertension & $367(62.7)$ & $164(40.7)$ & 0.0002 \\
\hline Diabetes mellitus & $156(26.7)$ & $52(12.9)$ & $<0.0001$ \\
\hline Hyperlipidemia & $178(30.4)$ & $94(23.3)$ & 0.069 \\
\hline tHcy $(\mu \mathrm{mol} / \mathrm{L})$ & $11.18 \pm 6.81$ & $10.06 \pm 4.20$ & 0.004 \\
\hline Folate (nmol/L) & $6.99 \pm 5.14$ & $8.55 \pm 5.96$ & $<0.0001$ \\
\hline Vitamin $B_{12}(p g / m L)$ & $747.10 \pm 616.70$ & $744.70 \pm 669.67$ & 0.905 \\
\hline Total cholesterol (mg/dL) & $191.09 \pm 40.39$ & $193.28 \pm 37.74$ & 0.353 \\
\hline Triglycerides (mg/dL) & $154.39 \pm 114.25$ & $147.24 \pm 90.61$ & 0.592 \\
\hline $\operatorname{PLT}\left(10^{3} / \mu \mathrm{L}\right)$ & $249.22 \pm 87.57$ & $243.10 \pm 67.35$ & 0.240 \\
\hline PT (sec) & $11.78 \pm 0.98$ & $11.77 \pm 0.80$ & 0.875 \\
\hline $\mathrm{aPTT}(\mathrm{sec})$ & $30.47 \pm 4.43$ & $33.42 \pm 18.58$ & $<0.001$ \\
\hline Fibrinogen (mg/dL) & $424.74 \pm 130.82$ & $94.45 \pm 44.03$ & $<0.001$ \\
\hline Antithrombin (\%) & $94.09 \pm 18.82$ & $400.17 \pm 120.45$ & $<0.001$ \\
\hline BUN (mg/dL) & $15.86 \pm 6.10$ & $15.78 \pm 4.93$ & 0.828 \\
\hline Uric acid (mg/dL) & $4.67 \pm 1.55$ & $4.64 \pm 1.44$ & 0.733 \\
\hline
\end{tabular}

Values are presented as number (\%) or mean \pm SD.

tHcy. total homocysteine; PLT, platelet count; PT, prothrombin time; aPTT, activated partial thromboplastin time; BUN, blood urea nitrogen.

${ }^{*} P$-values were calculated using the two-sided t-test for continuous variables and the chi-square test for categorical variables.

were analyzed by the polymerase chain reaction-restriction fragment length polymorphism (PCR-RFLP) method. The PCR conditions for miRNA biogenesis genes polymorphism analyses are presented in Supplementary Table 1. To validate RFLP findings, 30\% of the PCR assays for each polymorphism were randomly selected and repeated, followed by DNA sequencing. Sequencing was performed using an ABI 3730xI DNA Analyzer (Applied Biosystems, Foster City, CA, USA). The concordance of these quality control samples with the RFLP results was 100\%.

\section{Post-stroke mortality}

To evaluate the association between miRNA biogenesis gene polymorphisms and long-term prognosis after ischemic stroke, survival time from stroke onset to death was tracked. The dates of death for each stroke patient $(n=585)$ were ascertained using death certificates from the Korean National Statistical Office. Patients who were alive on December 31, 2013 were excluded from the study.

\section{Statistical analysis}

Genotype and allele combination frequencies in ischemic stroke cases and controls were compared using multivariate logistic regression models and Fisher exact test, respectively. Allele fre- quencies were calculated to identify deviations from HardyWeinberg equilibrium using $P=0.05$ as a threshold. Odds ratios, adjusted odds ratios (AORs), and 95\% confidence intervals (Cls) were used to measure the strength of association between various genotypes and ischemic stroke. The association between miRNA biogenesis gene SNPs and post-stroke mortality was evaluated using Cox proportional hazard regression. The proportional hazards assumption was tested using a $\log (-\log [$ survival] $)$ plot and interaction for follow-up time in a time-dependent Cox regression model, which was found to be satisfactory. For multivariate analyses, logistic regression analyses were used to adjust for possible confounders, including age, sex, hypertension, diabetes mellitus, hyperlipidemia, and smoking. Statistical significance was accepted at the $P<0.05$ level. ${ }^{28,29}$

\section{Results}

\section{Baseline characteristics}

The demographic characteristics of the 585 stroke cases and 403 controls are presented in Table 1. Of the stroke and control samples, $41.5 \%$ and $41.7 \%$, respectively, were men, and the mean ages of stroke cases and controls were $62.7 \pm 10.9$ and $62.8 \pm 10.6$ years, respectively. 
Table 2. Comparison of DICER, DROSHA, RAN, and XPO5 polymorphisms between ischemic stroke patients and controls subjects

\begin{tabular}{|c|c|c|c|c|c|c|c|c|}
\hline Genotype & $\begin{array}{l}\text { Controls } \\
(n=403)\end{array}$ & $\begin{array}{c}\text { Cases } \\
(n=585)\end{array}$ & COR $(95 \% \mathrm{Cl})$ & $P^{*}$ & $P^{+}$ & AOR $(95 \% \mathrm{Cl})^{+}$ & $P^{\S}$ & $P^{+}$ \\
\hline \multicolumn{9}{|l|}{ DICER rs13078 A>T } \\
\hline $\mathrm{AA}$ & $360(89.3)$ & $527(90.1)$ & 1.000 (reference) & & & 1.000 (reference) & & \\
\hline AT & $43(10.7)$ & $55(9.4)$ & $0.874(0.574-1.331)$ & 0.530 & 0.530 & $0.926(0.596-1.439)$ & 0.733 & 0.733 \\
\hline$\Pi$ & 0 & $3(0.5)$ & NA & & & NA & 0.994 & 0.994 \\
\hline Dominant (AA vs. $A T+T$ ) & & & $0.921(0.608-1.398)$ & 0.700 & 0.700 & $0.978(0.633-1.511)$ & 0.920 & 0.920 \\
\hline Recessive (AA+AT vs. T) & & & NA & & & NA & 0.994 & 0.994 \\
\hline HWE- $P$ & 0.258 & 0.238 & & & & & & \\
\hline \multicolumn{9}{|l|}{ DICER rs3742330 A>G } \\
\hline AA & $148(36.7)$ & 169 (28.9) & 1.000 (reference) & & & 1.000 (reference) & & \\
\hline$A G$ & $180(44.7)$ & $280(47.9)$ & $1.362(1.020-1.820)$ & 0.036 & 0.129 & 1.313 (0.969-1.779) & 0.079 & 0.237 \\
\hline GG & 75 (18.6) & $136(23.2)$ & $1.588(1.110-2.272)$ & 0.011 & 0.043 & $1.459(1.000-2.126)$ & 0.050 & 0.100 \\
\hline Dominant ( $\mathrm{AA}$ vs. $\mathrm{AG}+\mathrm{GG}$ ) & & & 1.429 (1.090-1.872) & 0.010 & 0.057 & $1.360(1.024-1.807)$ & 0.034 & 0.102 \\
\hline Recessive (AA+AG vs. GG) & & & $1.325(0.966-1.817)$ & 0.081 & 0.135 & $1.254(0.902-1.745)$ & 0.178 & 0.356 \\
\hline HWE-P & 0.125 & 0.337 & & & & & & \\
\hline \multicolumn{9}{|l|}{ DROSHA rs6877842 C>G } \\
\hline $\mathrm{CC}$ & $371(92.1)$ & $548(93.7)$ & 1.000 (reference) & & & 1.000 (reference) & & \\
\hline CG & $31(7.7)$ & $36(6.2)$ & $0.786(0.478-1.294)$ & 0.344 & 0.503 & $0.785(0.467-1.320)$ & 0.361 & 0.542 \\
\hline GG & $1(0.2)$ & $1(0.2)$ & $0.677(0.042-10.858)$ & 0.783 & 0.783 & $0.769(0.046-12.813)$ & 0.855 & 0.994 \\
\hline Dominant (CC vs. $\mathrm{CG}+\mathrm{GG}$ ) & & & $0.783(0.479-1.279)$ & 0.328 & 0.394 & $0.784(0.470-1.309)$ & 0.352 & 0.422 \\
\hline Recessive (CC+CG vs. GG) & & & $0.688(0.043-11.038)$ & 0.792 & 0.792 & $0.766(0.046-12.743)$ & 0.852 & 0.994 \\
\hline HWE-P & 0.680 & 0.614 & & & & & & \\
\hline \multicolumn{9}{|l|}{ DROSHA rs10719 T>C } \\
\hline$\pi$ & $228(56.6)$ & $304(52.0)$ & 1.000 (reference) & & & 1.000 (reference) & & \\
\hline TC & $158(39.2)$ & $235(40.2)$ & $1.116(0.856-1.454)$ & 0.419 & 0.503 & $1.102(0.835-1.455)$ & 0.492 & 0.590 \\
\hline $\mathrm{CC}$ & $17(4.2)$ & $46(7.9)$ & $2.029(1.134-3.633)$ & 0.017 & 0.043 & $2.038(1.113-3.730)$ & 0.021 & 0.994 \\
\hline Dominant (T vs. TC+CC) & & & $1.204(0.933-1.554)$ & 0.153 & 0.306 & $1.193(0.913-1.558)$ & 0.196 & 0.294 \\
\hline Recessive $(\Pi+\mathrm{TC}$ vs. $\mathrm{CC})$ & & & 1.938 (1.094-3.432) & 0.023 & 0.115 & $2.001(1.106-3.621)$ & 0.022 & 0.132 \\
\hline HWE-P & 0.107 & 0.950 & & & & & & \\
\hline \multicolumn{9}{|l|}{ RAN rs $14035 \mathrm{C}>\mathrm{T}$} \\
\hline $\mathrm{CC}$ & $240(59.6)$ & $369(63.1)$ & 1.000 (reference) & & & 1.000 (reference) & & \\
\hline $\mathrm{CT}$ & $149(37.0)$ & $192(32.8)$ & $0.838(0.641-1.097)$ & 0.198 & 0.396 & $0.803(0.606-1.064)$ & 0.127 & 0.254 \\
\hline$\Pi$ & $14(3.5)$ & $24(4.1)$ & 1.115 (0.566-2.198) & 0.753 & 0.783 & $1.106(0.545-2.244)$ & 0.780 & 0.994 \\
\hline Dominant (CC vs. $\mathrm{CT}+\mathrm{T}$ ) & & & $0.862(0.664-1.118)$ & 0.263 & 0.394 & $0.830(0.632-1.091)$ & 0.181 & 0.294 \\
\hline Recessive (CC+CT vs. T) & & & $1.189(0.607-2.327)$ & 0.614 & 0.768 & $1.198(0.597-2.403)$ & 0.611 & 0.917 \\
\hline HWE- $P$ & 0.114 & 0.876 & & & & & & \\
\hline \multicolumn{9}{|l|}{ XP05 rs11077 A>C } \\
\hline AA & $319(79.2)$ & $497(85.0)$ & 1.000 (reference) & & & 1.000 (reference) & & \\
\hline$A C$ & $79(19.6)$ & $87(14.9)$ & $0.707(0.505-0.989)$ & 0.043 & 0.129 & 0.707 (0.497-1.005) & 0.053 & 0.237 \\
\hline $\mathrm{CC}$ & $5(1.2)$ & $1(0.2)$ & $0.128(0.015-1.104)$ & 0.062 & 0.103 & $0.101(0.011-0.951)$ & 0.045 & 0.100 \\
\hline Dominant (AA vs. $A C+C C$ ) & & & $0.672(0.483-0.936)$ & 0.019 & 0.057 & $0.669(0.473-0.945)$ & 0.023 & 0.102 \\
\hline Recessive $(A A+A C$ vs. $C C)$ & & & $0.136(0.016-1.171)$ & 0.069 & 0.135 & $0.116(0.013-1.078)$ & 0.058 & 0.174 \\
\hline HWE- $P$ & 0.965 & 0.161 & & & & & & \\
\hline
\end{tabular}

Values are presented as number (\%).

RAN, Ran GTPase; XPO5, exportin 5; COR, crude odds ratio; Cl, confidence interval; AOR, adjusted odds ratio; NA, not available; HWE, Hardy-Weinberg equilibrium. ${ }^{*}$ Calculated by chi-square test according to genotype frequencies; ${ }^{+} P$-value calculated by false discovery rate test; ${ }^{*}$ Odds ratios adjusted for age, sex, hypertension, diabetes mellitus, hyperlipidemia, and smoking status, ${ }^{\S} P$-value calculated by logistics regression analysis. 


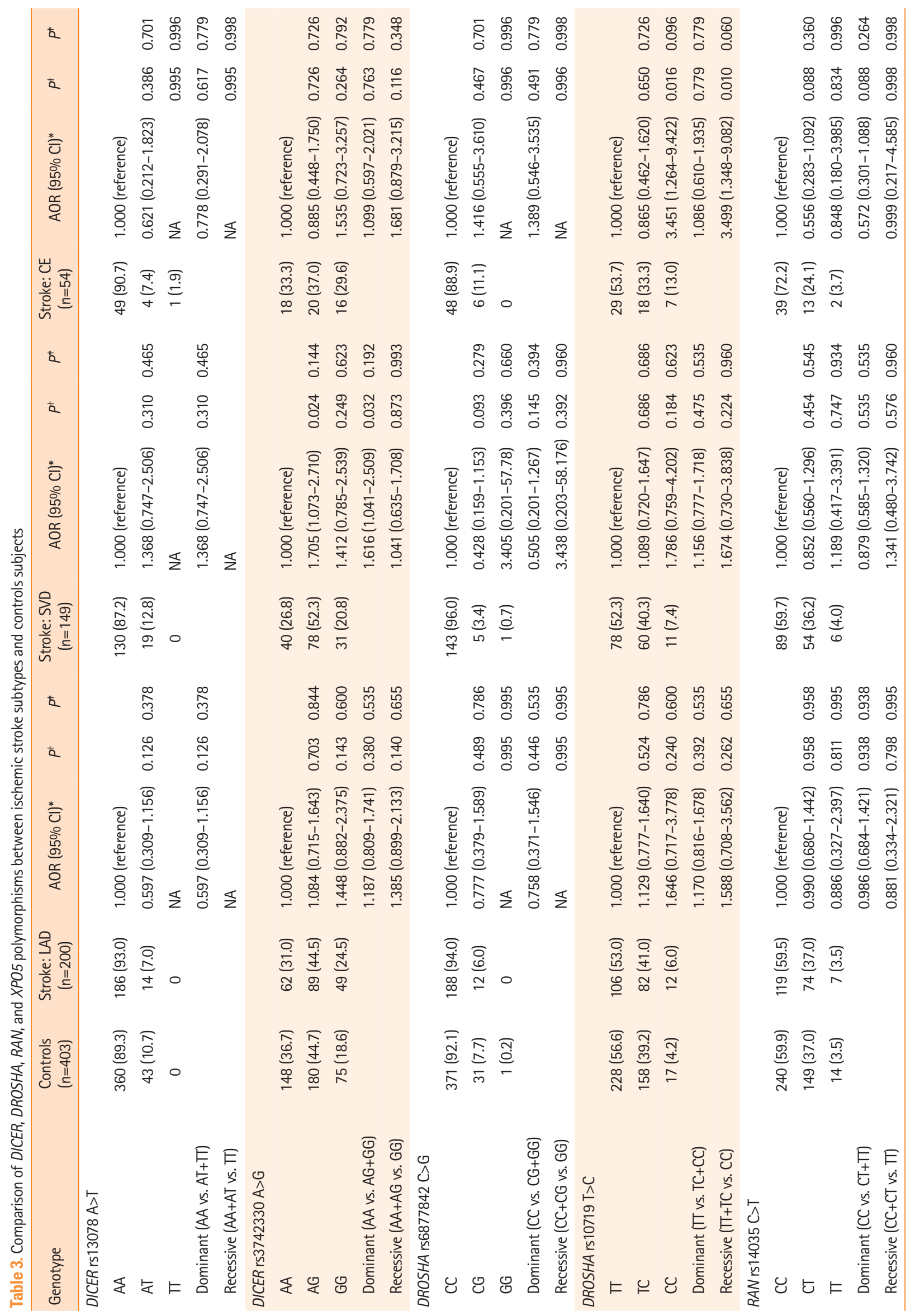




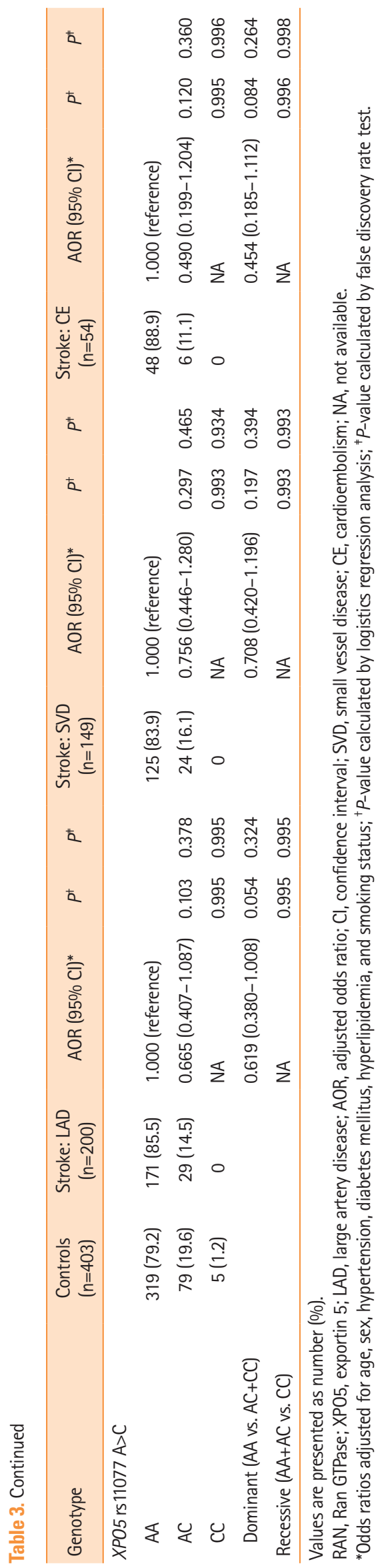

Genotype frequencies of the miRNA biogenesis genes polymorphisms

Table 2 provides the genotype distributions of the six miRNA biogenesis gene polymorphisms in ischemic stroke cases and controls. The DICER rs3742330A>G polymorphism was associated with greater odds of ischemic stroke (AA vs. GG: AOR, $1.459 ; 95 \% \mathrm{Cl}, 1.000$ to $2.126 ; P=0.050$; and $A A$ vs. $A G+G G$ : $A O R, 1.360 ; 95 \% \mathrm{Cl}, 1.024$ to $1.807 ; P=0.034)$. The DROSHA rs10719T>C polymorphism was also associated with greater odds of ischemic stroke (T vs. CC: AOR, 2.038; $95 \% \mathrm{Cl}, 1.113$ to $3.730 ; P=0.021$; and $\Pi+\mathrm{TC}$ vs. $\mathrm{CC}$ : $\mathrm{AOR}, 2.001 ; 95 \% \mathrm{Cl}$, 1.106 to $3.621 ; P=0.022)$. By contrast, the $X P 05$ rs $11077 A>C$ polymorphism was associated with lower odds of stroke (AA vs. CC: AOR, $0.101 ; 95 \% \mathrm{Cl}, 0.011$ to $0.951 ; P=0.045$; and AA vs. $\mathrm{AC}+\mathrm{CC}$ : $\mathrm{AOR}, 0.669 ; 95 \% \mathrm{Cl}, 0.473$ to $0.945 ; P=0.023)$. The frequency of the DICER1 rs13078A $>$ T, DROSHA ABI 3730xI DNA Analyzer $C>G$, and $R A N$ rs $14035 C>T$ polymorphisms was not significantly different between stroke cases and controls. To examine whether the effect of each polymorphism was confined to a specific subtype, stroke patients were separated into three subgroups ( $L A D, S V D$, and CE) according to TOAST classifications (Table 3). Comparisons were also performed with control subjects and single versus multiple SVD patients (Supplementary Table 2). LAD was not significantly associated with a ny of the polymorphisms examined. However, the DICER 1 rs3742330A $>G$ polymorphism was significantly associated with SVD (AA vs. AG: AOR, 1.705; 95\% Cl, 1.073 to 2.710; $P=0.024$; and $A A$ vs. $A G+G G: A O R, 1.616 ; 95 \% \mathrm{Cl}, 1.041$ to 2.509; $P=0.032$ ). In addition, the DROSHA rs $10719 T>C$ polymorphism was significantly associated with $C E$ (TT vs. CC: AOR, 3.451; 95\% Cl, 1.264 to $9.422 ; P=0.016$; and $\Pi+\mathrm{TC}$ vs. $\mathrm{CC}$ : AOR, 3.499; $95 \% \mathrm{Cl}, 1.348$ to $9.082 ; P=0.010$ ).

\section{Combined effects of miRNA biogenesis gene polymorphisms and clinical factors}

Stratified analysis of each clinical factor was performed to confirm the influence of clinical factors on the occurrence of ischemic stroke. However, no significant clinical factors were found to affect ischemic stroke risk (Supplementary Table 3). Therefore, a combined effect analysis was conducted to ascertain the effect of stroke and genotype on the prevalence of ischemic stroke. A synergistic effect was found for ischemic stroke prevalence between clinical factors (hypertension and diabetes mellitus) and miRNA biogenesis gene polymorphisms (Figure 1). The DROSHA rs 10719 CC genotype was associated with stroke in individuals with hypertension (AOR, 4.781; 95\% $\mathrm{Cl}, 1.981$ to 11.54). Diabetes mellitus combined with the DROSHA rs 10719 CC genotype yielded the most significant associa- 

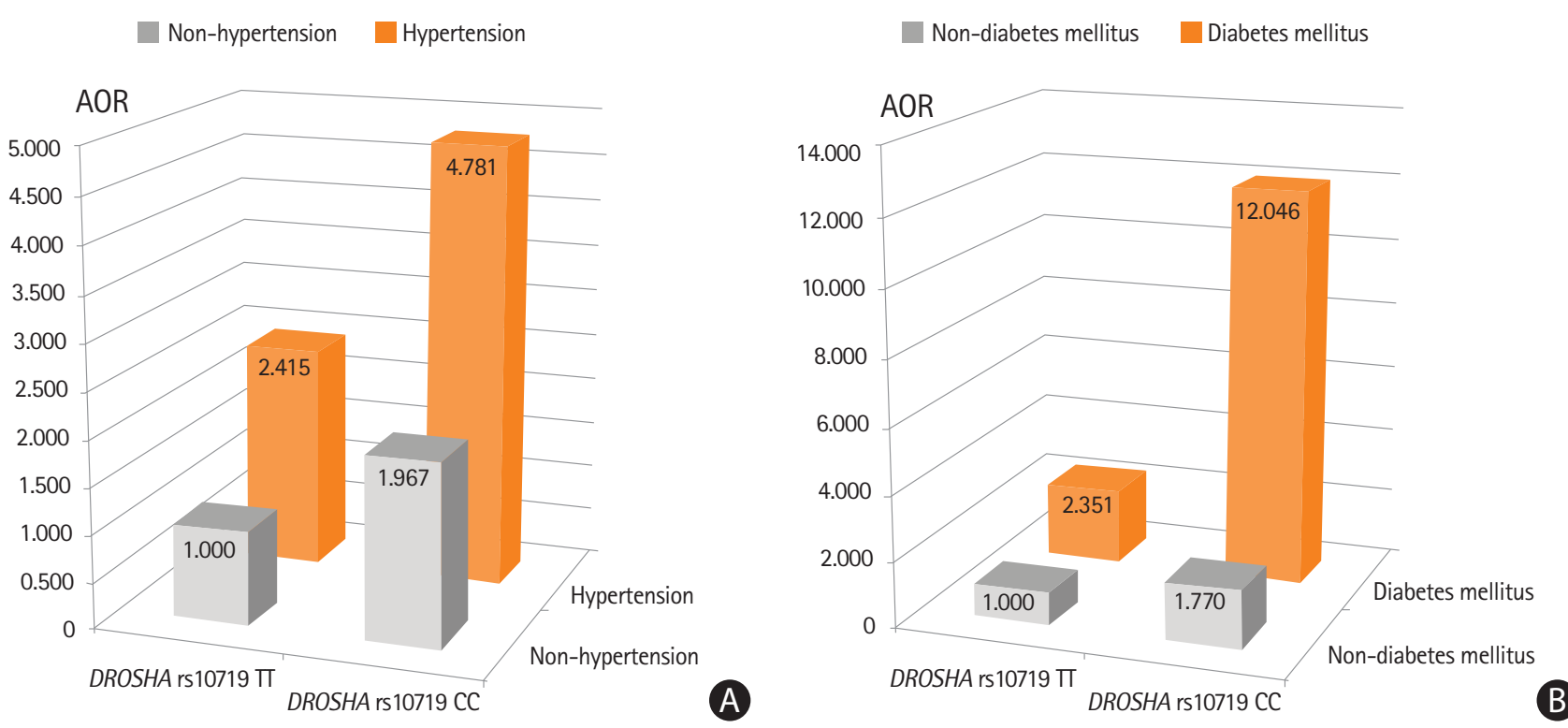

Figure 1. The effects of DROSHA rs10719 T>C variant on ischemic stroke development modulated by clinical factors. (A) The synergistic effect for ischemic stroke susceptibility in DROSHA rs10719CC with hypertension (adjusted odds ratio [AOR], 4.781), DROSHA rs10719CC with non-hypertension (AOR, 1.967), or DROSHA rs 10719TT with hypertension (AOR, 2.415). (B) DROSHA rs10719 T>C was associated with elevated ischemic stroke prevalence, in the case of DROSHA rs10719CC, with diabetes mellitus (AOR, 12.046), DROSHA rs10719CC, with non-diabetes mellitus (AOR, 1.770), and DROSHA rs10719T, with diabetes mellitus (AOR, 2.351).

tion with stroke (AOR, 12.05; 95\% $\mathrm{Cl}, 1.541$ to 94.19). Other gene-clinical factor combinations were not significantly associated with ischemic stroke (Supplementary Tables 4-6). The effects of miRNA biogenesis gene genotypes on blood coagulation status were evaluated by measuring platelet proportion, prothrombin time, activated partial thromboplastin time (aPT), fibrinogen, and antithrombin (Supplementary Table 7). It was found that the DROSHA rs 10719 CC genotype was significantly associated with elevated aPT (T vs. CC: $P=0.007$; TC vs. CC: $P=0.019$ ) (Supplementary Figure $1 A$ ) and antithrombin (TC vs. CC: $P=0.039$ ) (Supplementary Figure 1B). The other coagulant factors did not exhibit any statistically significant associations with any of the tested genotypes.

\section{Polymorphisms in miRNA biogenesis genes versus post-stroke mortality}

To evaluate the association between miRNA biogenesis gene polymorphisms and post-stroke mortality, Cox regression analysis was performed on the 585 patients with total ischemic stroke according to TOAST subtype (Figure 2 and Supplementary Table 8). During a mean follow-up of $4.80 \pm 2.11$ years, 99 of the stroke patients died. In the multivariate Cox proportional hazard regression models, a significant association was found between RAN rs 14035 and survival of LAD patients with ischemic stroke (CC vs. TT: adjusted hazard ratio [HR], 5.978; $P=0.015$; and $C C+C T$ vs. $T$ : adjusted HR, 3.946; $P=0.034$ ) (Fig- ure 2). A significant association was also found between $R A N$ rs14035 and SVD in our analysis of ischemic stroke subtypes (CC vs. $T$ : adjusted HR, 9.403; $P=0.015$; and $C C+C T$ vs. $\Pi$ : adjusted $H R, 5.223 ; P=0.039$ ) (Figure 2). However, survival analysis was performed by Cox proportional-hazards regression based on the stepwise method for confirming covariant effect. A stepwise Cox regression analysis of ischemic stroke-related survival is shown in Supplementary Table 9. Mortality in SVD subgroup of ischemic stroke cases was associated with age and RAN rs14039 polymorphism status.

\section{Supplemental data}

Gene-gene interaction analyses were performed for miRNA biogenesis gene polymorphisms to identify combinations that have synergistic effects on stroke risk (Supplementary Tables 10 and 11). Some variants and allele combinations exhibited significant associations. However, the meaning of these associations should be interpreted with caution because the sample size is rather small.

\section{Discussion}

A recent study indicated that miR-221 and miR-222 modulate the angiogenic properties of human umbilical vein endothelial cells. ${ }^{30}$ However, the function and biosynthesis of miRNAs in endothelial cell biology remains unclear. Therefore, in this 

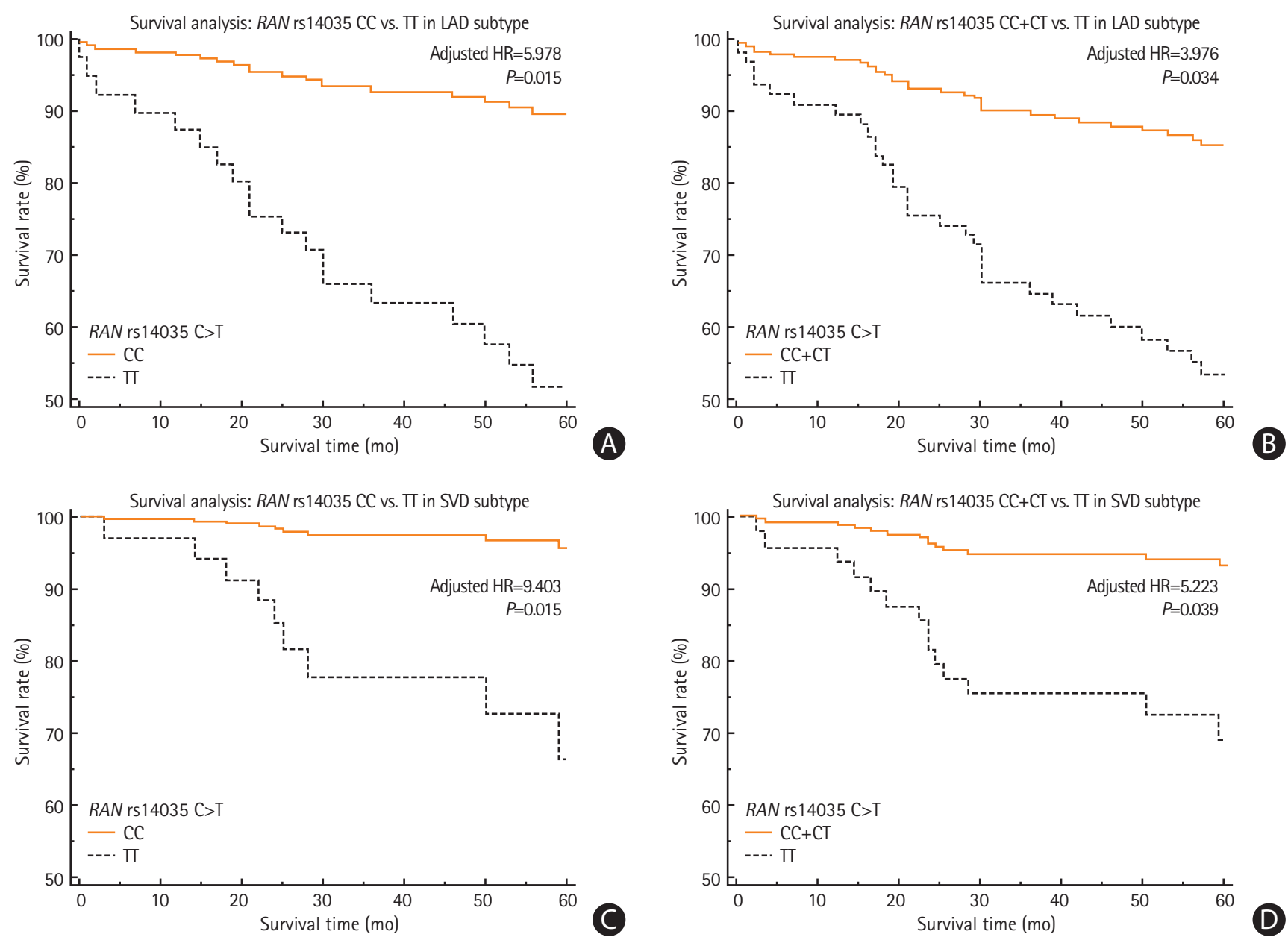

Figure 2. Survival plot from a Cox proportional hazards model with RAN rs14035C >T polymorphisms in ischemic stroke. Survival curve of patients grouped by large artery disease (LAD) subtype based on (A) RAN rs14035CC vs. RAN rs14035T genotypes and (B) RAN rs14035CC+CT vs. RAN rs14035T genotypes. In addition, survival curve of patients grouped by SVD subtype based on (C) RAN rs14035CC vs. RAN rs14035T genotypes and (D) RAN rs14035CC+CT vs. RAN rs14035T genotypes. $H R$, hazard ratio.

study of ischemic stroke, we focused on miRNA biogenesis genes, such as DICER1, DROSHA, XPO5, and RAN, which are related to endothelial miRNA expression and angiogenesis. ${ }^{31,32}$ We evaluated six polymorphisms in DICER1, DROSHA, XPO5, and $R A N$ genes essential for miRNA biosynthesis, ${ }^{33-35}$ in ischemic stroke cases and controls. We found that polymorphisms in DICER and DROSHA, both of which are involved in angiogenesis and coagulation mechanisms, ${ }^{36-38}$ were linked to ischemic stroke. Polymorphisms in DICER, a gene already known to play a role in vascular growth and genesis, displayed the strongest association with ischemic stroke. For example, the DICER rs3742330 GG genotype was significantly more frequent in both overall stroke cases and subtype SVD cases than in controls. Moreover, the interplay between the DICER rs3742330 GG genotype and hyperlipidemia status was elevated stroke prevalence. The roles of DICER in angiogenesis and vascular growth have previously been investigated, and there is a re- ported association between DICER expression and healthy endothelial cell growth. ${ }^{39}$ Moreover, there is strong evidence that a functional DICER1-dependent pathway is essential for a healthy endothelial angiogenic response. All major steps of the angiogenic process, including adhesion, proliferation, migration, and capillary-like structure formation are compromised by disrupted DICER1 signaling in cerebromicrovascular endothelial cells, ${ }^{40,41}$ in addition to other cell types. ${ }^{32,38,42,43}$

DICER and DROSHA play crucial roles in vertebrate development. DICER1-deficient mice die early in development, between embryonic days 12.5 and 14.5, displaying impaired blood vessel and yolk sac formation. Similarly, zebrafish DICER mutant embryos display abnormal morphogenesis during gastrulation, brain formation, somatogenesis, and heart development. ${ }^{38}$ In addition, loss of DROSHA leads to vascular smooth muscle cells disorder followed by hypoplastic blood vessel walls, cardiomyopathy, and liver hemorrhage in mice between embryonic days 13.5 and 
14.5 , and causes embryonic mortality in affected mice. ${ }^{44} \mathrm{~A}$ number of studies have reported that DICER and DROSHA polymorphisms, including rs3742330 and rs10719, affect disease development and patient survival in various cancers. ${ }^{34,45-49}$ In addition, functional analysis of rs 1057035, which resides in the 3'-UTR of $D I C E R$, has revealed that the polymorphism affects hsa-miR574-3p targeting and DICER expression. ${ }^{50}$ The DROSHA rs 10719 polymorphism, which is located in the 3'-UTR of DROSHA, was associated with different DROSHA expression levels ${ }^{33}$ and presented different binding efficiency for the target site of hsa-miR$276 .{ }^{35,51}$ Furthermore, previous studies reported that DROSHA rs6877842 and rs640831 polymorphisms affected miRNA expression levels. ${ }^{34,52}$

There are several potential mechanisms linking DICER and DROSHA polymorphisms to ischemic disease. First, DICER and $D R O S H A$ polymorphisms may directly affect angiogenesis via endothelial cell growth or induce blood vessel defects in embryos, resulting in vascular abnormalities..$^{39,44}$ In a DICER and DROSHA knockout model, hemorrhaging during vascular smooth muscle cell development was observed. ${ }^{39,44}$ Moreover, DICER silencing in endothelial cells modulated the expression of several genes involved in endothelial biology, including nitric oxide synthase 3 , matrix metalloproteinase 2 (MMP-2), integrins- $v$ and -1 , fibronectin, endothelin receptor types $A$, endothelin 1, vascular endothelial cadherin, and caspase-3. Both integrins- $v$ and -1 are implicated in angiogenesis and endothelial survival, ${ }_{1}^{53}$ and MMP-2 participates in autocrine processes that influence hypoxia-induced migration and apoptotic death in endothelial cells. ${ }^{54}$ Additionally, DROSHA has a similar role to DICER in vascular smooth muscle cell survival through ERK1/2 and AKT regulation. ${ }^{44}$ Furthermore, previous studies identified that DROSHA influenced the regulation of miRNA expression. Transcription of certain miRNAs does not require DICER, but does need DROSHA (e.g., miR-1225 and miR-228). ${ }^{55}$ In addition, other miRNAs such as miR-877, miR-1224, and miR-1226 are independent of the canonical miRNA biogenesis pathway but dependent on the splicing process by DROSHA. ${ }^{56-58}$

Alternately, DICER and DROSHA may indirectly affect miRNA regulation via RNA interference. As noted above, DICER and DROSHA are involved in miRNA biogenesis. miRNAs have multiple mRNA targets, are important regulators of gene expression, and play important roles in the initiation and progression of diverse diseases including leukemia, rheumatoid arthritis, and multiple sclerosis..$^{59-62}$ In particular, miRNAs are known to affect the immune system and vasculature in ischemic stroke. 19,21,62 At present, it is not known whether DICER polymorphisms affect stroke risk by affecting DICER enzyme function or via RNA interference. Further in vitro studies are needed to distinguish between these two hypotheses.

Interestingly, the results of the current study indicate a significant association between increased mortality after stroke and the RAN rs14035 C>T polymorphism, after adjusting for age, sex, hypertension, hyperlipidemia, and smoking status. As we did not have data on causes of death, we cannot be certain that the high mortality in patients with RAN rs14035 Tा genotype was due to vascular events. However, analysis revealed that the RAN rs $14035 \pi$ genotype was significantly associated with the survival rate of ischemic stroke patients, supporting the likelihood of it also causing post-stroke mortality.

This was a case-control association study with 988 samples, but it has several limitations. First, although we found an association between XPO5 rs 11077 polymorphisms and stroke risk, there is still no hypothesized mechanism for the role of this polymorphism in ischemic stroke prevalence. Second, the weak associations observed between the DICER rs 13078, DROSHA rs6877842, and RAN rs14035 polymorphisms and ischemic stroke require replication. Third, some of the controls in our study were seeking medical attention; therefore, they were not completely healthy. However, recruitment of healthy participants with imaging and laboratory tests would markedly reduce the enrollment rate and including participants without imaging and laboratory tests may produce other vascular risk factor assessment biases. Finally, the study population was restricted to patients of Korean ethnicity.

\section{Conclusions}

We have identified an association between ischemic stroke susceptibility and polymorphisms in DICER rs3742330 and DROSHA rs10719, in addition to a significant association with the RAN rs 14035 polymorphism in post-stroke mortality. These findings may encourage research efforts focusing on the role of DICER and DROSHA in vascular development. We postulate that the DICER rs3742330 and DROSHA rs 10719 polymorphisms influence miRNA biosynthesis and therefore, miRNA post-transcriptional regulation during vascular endothelial cell growth, proliferation, and differentiation. However, the underlying mechanism remains to be elucidated in future research.

\section{Supplementary materials}

Supplementary materials related to this article can be found online at https://doi.org/10.5853/jos.2017.02586. 


\section{Disclosure}

The authors have no financial conflicts of interest.

\section{Acknowledgments}

This study was partially supported by National Research Foundation of Korea Grants funded by the Korean Government (NRF2015R1D1A1A09057432, NRF-2016R1D1A1B03930141, and NRF-2017R1D1A1B03029582) and by the Korea Health Technology R\&D Project through the Korea Health Industry Development Institute (KHIDI), funded by the Ministry of Health and Welfare, Republic of Korea (grant number: HI16C1559).

\section{References}

1. Kluijtmans LA, Young IS, Boreham CA, Murray L, McMaster D,

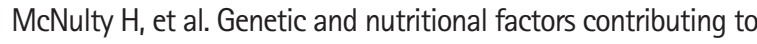
hyperhomocysteinemia in young adults. Blood 2003;101:24832488.

2. Gellekink $H$, den Heijer M, Heil SG, Blom HJ. Genetic determinants of plasma total homocysteine. Semin Vasc Med 2005;5:98-109.

3. Kitamura $A$, Iso $H$, Naito $Y$, lida $M$, Konishi $M$, Folsom $A R$, et al. High-density lipoprotein cholesterol and premature coronary heart disease in urban Japanese men. Circulation 1994;89: 2533-2539.

4. Iso $H$, Naito $Y$, Sato $S$, Kitamura A, Okamura $T$, Sankai $T$, et al. Serum triglycerides and risk of coronary heart disease among Japanese men and women. Am J Epidemiol 2001;153:490-499.

5. Kosch A, Koch HG, Heinecke A, Kurnik K, Heller C, Nowak-Göttl $U$, et al. Increased fasting total homocysteine plasma levels as a risk factor for thromboembolism in children. Thromb Haemost 2004;91:308-314.

6. Lee R, Frenkel EP. Hyperhomocysteinemia and thrombosis. Hematol Oncol Clin North Am 2003;17:85-102.

7. Ambros V. The functions of animal microRNAs. Nature 2004; 431:350-355.

8. Kim JH, Li LH, Cai H, Nguyen VH, Min JJ, Shin BA, et al. miRNA-105 and -128 function as rheostats modulating MMP-2 activities by downregulation of TIMP-2 and upregulation of MT1-MMP. Genes Genom 2016;38:217-223.

9. Lee G, Choi YC, Byun Y, Yoon S, Jeong Y, Yoon J, et al. The seed sequence is necessary but insufficient for downregulation of target genes by miR-608. Genes Genom 2016;38:567-572.

10. Chen $K$, Rajewsky N. The evolution of gene regulation by transcription factors and microRNAs. Nat Rev Genet 2007;8:93103.
11. Bartel DP. MicroRNAs: genomics, biogenesis, mechanism, and function. Cell 2004;116:281-297.

12. Guarnieri DJ, DiLeone RJ. MicroRNAs: a new class of gene regulators. Ann Med 2008;40:197-208.

13. Carthew RW, Sontheimer EJ. Origins and mechanisms of miRNAs and siRNAs. Cell 2009;136:642-655.

14. Nicoloso MS, Calin GA. MicroRNA involvement in brain tumors: from bench to bedside. Brain Pathol 2008;18:122-129.

15. Lu J, Getz G, Miska EA, Alvarez-Saavedra E, Lamb J, Peck D, et al. MicroRNA expression profiles classify human cancers. Nature 2005;435:834-838.

16. Hill JM, Pogue Al, Lukiw WJ. Pathogenic microRNAs common to brain and retinal degeneration: recent observations in Alzheimer's disease and age-related macular degeneration. Front Neurol 2015;6:232.

17. Kim J, Inoue K, Ishii J, Vanti WB, Voronov SV, Murchison E, et al. A microRNA feedback circuit in midbrain dopamine neurons. Science 2007;317:1220-1224.

18. Beveridge NJ, Tooney PA, Carroll AP, Gardiner E, Bowden N, Scott RJ, et al. Dysregulation of miRNA 181b in the temporal cortex in schizophrenia. Hum Mol Genet 2008;17:1156-1168.

19. Khoshnam SE, Winlow W, Farbood Y, Moghaddam HF, Farzaneh M. Emerging roles of microRNAs in ischemic stroke: as possible therapeutic agents. J Stroke 2017;19:166-187.

20. Jeyaseelan $K$, Lim $K Y$, Armugam A. MicroRNA expression in the blood and brain of rats subjected to transient focal ischemia by middle cerebral artery occlusion. Stroke 2008;39:959-966.

21. Dharap A, Bowen K, Place R, Li LC, Vemuganti R. Transient focal ischemia induces extensive temporal changes in rat cerebral microRNAome. J Cereb Blood Flow Metab 2009;29:675687.

22. Bazan HA, Hatfield SA, O'Malley CB, Brooks AJ, Lightell D Jr, Woods TC. Acute loss of miR-221 and miR-222 in the atherosclerotic plaque shoulder accompanies plaque rupture. Stroke 2015;46:3285-2387.

23. McManus DD, Freedman JE. MicroRNAs in platelet function and cardiovascular disease. Nat Rev Cardiol 2015;12:711717.

24. Ksiazek-Winiarek DJ, Kacperska MJ, Glabinski A. MicroRNAs as novel regulators of neuroinflammation. Mediators Inflamm 2013;2013:172351.

25. Zamore PD, Haley B. Ribo-gnome: the big world of small RNAs. Science 2005;309:1519-1524.

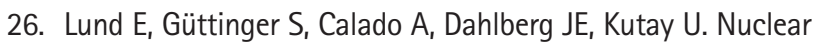
export of microRNA precursors. Science 2004;303:95-98.

27. Bartel DP, Chen CZ. Micromanagers of gene expression: the potentially widespread influence of metazoan microRNAs. Nat Rev Genet 2004;5:396-400. 
28. Kim OJ, Hong SH, Oh SH, Kim TG, Min KT, Oh D, et al. Association between VEGF polymorphisms and homocysteine levels in patients with ischemic stroke and silent brain infarction. Stroke 2011;42:2393-2402.

29. Jeon YJ, Kim OJ, Kim SY, Oh SH, Oh D, Kim OJ, et al. Association of the miR-146a, miR-149, miR-196a2, and miR-499 polymorphisms with ischemic stroke and silent brain infarction risk. Arterioscler Thromb Vasc Biol 2013;33:420-430.

30. Poliseno L, Tuccoli A, Mariani L, Evangelista M, Citti L, Woods $\mathrm{K}$, et al. MicroRNAs modulate the angiogenic properties of HUVECs. Blood 2006;108:3068-3071.

31. Kuehbacher A, Urbich C, Zeiher AM, Dimmeler S. Role of Dicer and Drosha for endothelial microRNA expression and angiogenesis. Circ Res 2007;101:59-68.

32. Saxena A, Tabin CJ. miRNA-processing enzyme Dicer is necessary for cardiac outflow tract alignment and chamber septation. Proc Natl Acad Sci U S A 2010;107:87-91.

33. Saeki M, Watanabe M, Inoue N, Tokiyoshi E, Takuse Y, Arakawa $Y$, et al. DICER and DROSHA gene expression and polymorphisms in autoimmune thyroid diseases. Autoimmunity 2016;49:514-522.

34. Rotunno M, Zhao Y, Bergen AW, Koshiol J, Burdette L, Rubagotti $M$, et al. Inherited polymorphisms in the RNA-mediated interference machinery affect microRNA expression and lung cancer survival. Br J Cancer 2010;103:1870-1874.

35. Zhang Y, Cao AL, Dong C. rs 10719 polymorphism located within DROSHA 3'-untranslated region is responsible for development of primary hypertension by disrupting binding with microRNA-27b. Med Sci Monit 2017;23:911-918.

36. Sung H, Lee KM, Choi JY, Han S, Lee JY, Li L, et al. Common genetic polymorphisms of microRNA biogenesis pathway genes and risk of breast cancer: a case-control study in Korea. Breast Cancer Res Treat 2011;130:939-951.

37. Albinsson S, Suarez Y, Skoura A, Offermanns S, Miano JM, Sessa WC. MicroRNAs are necessary for vascular smooth muscle growth, differentiation, and function. Arterioscler Thromb Vasc Biol 2010;30:1118-1126.

38. Yang WJ, Yang DD, Na S, Sandusky GE, Zhang Q, Zhao G. Dicer is required for embryonic angiogenesis during mouse development. J Biol Chem 2005;280:9330-9335.

39. Ungvari Z, Tucsek Z, Sosnowska D, Toth P, Gautam T, Podlutsky $A$, et al. Aging-induced dysregulation of dicer1-dependent microRNA expression impairs angiogenic capacity of rat cerebromicrovascular endothelial cells. J Gerontol A Biol Sci Med Sci 2013;68:877-891.

40. Asada $S$, Takahashi $T$, Isodono $K$, Adachi A, Imoto $H$, Ogata $T$, et al. Downregulation of Dicer expression by serum withdrawal sensitizes human endothelial cells to apoptosis. Am J
Physiol Heart Circ Physiol 2008;295:H2512-H2521.

41. Suárez Y, Fernández-Hernando $C, Y u$ J, Gerber SA, Harrison $K D$, Pober JS, et al. Dicer-dependent endothelial microRNAs are necessary for postnatal angiogenesis. Proc Natl Acad Sci USA 2008;105:14082-14087.

42. Suárez Y, Fernández-Hernando C, Pober JS, Sessa WC. Dicer dependent microRNAs regulate gene expression and functions in human endothelial cells. Circ Res 2007;100:1164-1173.

43. Lin J, Horikawa Y, Tamboli P, Clague J, Wood CG, Wu X. Genetic variations in microRNA-related genes are associated with survival and recurrence in patients with renal cell carcinoma. Carcinogenesis 2010;31:1805-1812.

44. Fan $P_{1}$ Chen $Z$, Tian $P_{1}$ Liu $W$, Jiao $Y, X u e ~ Y$, et al. miRNA biogenesis enzyme Drosha is required for vascular smooth muscle cell survival. PLoS One 2013;8:e60888.

45. Li $X$, Tian $X$, Zhang $B$, Zhang $Y$, Chen J. Variation in dicer gene is associated with increased survival in T-cell lymphoma. PLoS One 2012;7:e51640.

46. Clague J, Lippman SM, Yang H, Hildebrandt MA, Ye Y, Lee JJ, et al. Genetic variation in MicroRNA genes and risk of oral premalignant lesions. Mol Carcinog 2010;49:183-189.

47. Merritt WM, Bar-Eli M, Sood AK. The dicey role of Dicer: implications for RNAi therapy. Cancer Res 2010;70:2571-2574.

48. Ma H, Yuan $H$, Yuan Z, Yu C, Wang R, Jiang Y, et al. Genetic variations in key microRNA processing genes and risk of head and neck cancer: a case-control study in Chinese population. PLoS One 2012;7:e47544.

49. Khan S, Greco D, Michailidou K, Milne RL, Muranen TA, Heik-

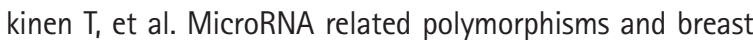
cancer risk. PLoS One 2014;9:e109973.

50. Stupack DG, Cheresh DA. Apoptotic cues from the extracellular matrix: regulators of angiogenesis. Oncogene 2003;22:90229029.

51. Kertesz M, lovino N, Unnerstall U, Gaul U, Segal E. The role of site accessibility in microRNA target recognition. Nat Genet 2007;39:1278-1284.

52. Martin-Guerrero I, Gutierrez-Camino A, Lopez-Lopez E, Bilbao-Aldaiturriaga N, Pombar-Gomez $M$, Ardanaz $M$, et al. Genetic variants in miRNA processing genes and pre-miRNAs are associated with the risk of chronic lymphocytic leukemia. PLoS One 2015;10:e0118905.

53. Ben-Yosef Y, Miller A, Shapiro S, Lahat N. Hypoxia of endothelial cells leads to MMP-2-dependent survival and death. Am J Physiol Cell Physiol 2005;289:C1321-C1331.

54. Calin GA, Dumitru CD, Shimizu M, Bichi R, Zupo $S$, Noch $E_{\text {, et }}$ al. Frequent deletions and down-regulation of micro- RNA genes miR15 and miR16 at 13q14 in chronic lymphocytic leukemia. Proc Natl Acad Sci U S A 2002;99:15524-15529. 
55. Havens MA, Reich AA, Duelli DM, Hastings ML. Biogenesis of mammalian microRNAs by a non-canonical processing pathway. Nucleic Acids Res 2012;40:4626-4640.

56. Sibley CR, Seow Y, Saayman S, Dijkstra KK, El Andaloussi S, Weinberg MS, et al. The biogenesis and characterization of mammalian microRNAs of mirtron origin. Nucleic Acids Res 2012;40:438-448.

57. Dai L, Chen K, Youngren B, Kulina J, Yang A, Guo Z, et al. Cytoplasmic Drosha activity generated by alternative splicing. Nucleic Acids Res 2016;44:10454-10466.

58. Liu YP, Vink MA, Westerink JT, Ramirez de Arellano E, Konstantinova P, Ter Brake 0 , et al. Titers of lentiviral vectors encoding shRNAs and miRNAs are reduced by different mechanisms that require distinct repair strategies. RNA 2010;16:13281339.
59. Pauley KM, Satoh M, Chan AL, Bubb MR, Reeves WH, Chan EK. Upregulated miR-146a expression in peripheral blood mononuclear cells from rheumatoid arthritis patients. Arthritis Res Ther 2008;10:R101.

60. Du C, Liu C, Kang J, Zhao G, Ye Z, Huang S, et al. MicroRNA miR-326 regulates $\mathrm{TH}-17$ differentiation and is associated with the pathogenesis of multiple sclerosis. Nat Immunol 2009;10:1252-1259.

61. O'Connell RM, Rao DS, Chaudhuri AA, Baltimore D. Physiological and pathological roles for microRNAs in the immune system. Nat Rev Immunol 2010;10:111-122.

62. Liu DZ, Tian Y, Ander BP, Xu H, Stamova BS, Zhan X, et al. Brain and blood microRNA expression profiling of ischemic stroke, intracerebral hemorrhage, and kainate seizures. J Cereb Blood Flow Metab 2010;30:92-101. 
Supplementary Table 1. PCR-RFLP condition for microRNA machinery genes polymorphism

\begin{tabular}{|c|c|c|c|c|c|}
\hline SNP & Ref. gene & Polymorphism & Forward primer $\left(5^{\prime}-3^{\prime}\right)$ & Reverse primer $\left(5^{\prime}-3^{\prime}\right)$ & $\begin{array}{l}\text { Restriction } \\
\text { enzyme }^{*}\end{array}$ \\
\hline rs13078 & \multirow{2}{*}{ DICER } & $A>T$ & 5'-CTA GTT TTC CTG CAG ACA ATG CA-3' & 5'-GTA ATG CAC ATT CAC CAA AGT CA-3' & $\mathrm{Bccl}$ \\
\hline rs3742330 & & $A>G$ & 5'- GGT CTC AGT TTG GTG GCT TC -3' & 5'- CCT GCC TTG ACA ACA TGA AA -3' & Ban II \\
\hline rs10719 & \multirow{2}{*}{ DROSHA } & $\mathrm{T}>\mathrm{C}$ & 5'-CTA GTT TTC CTG CAG ACA ATG CA-3' & 5'-GTA ATG CAC ATT CAC CAA AGT CA-3' & Dra III \\
\hline rs6877842 & & $\mathrm{G}>\mathrm{C}$ & 5'-GGG CGC AAA AAC ATG AGT GAC-3' & 5'-TCC TCT CCA CAG CAA CGG AAT A-3' & Sau 961 \\
\hline rs14035 & RAN & $C>T$ & 5'-GAA GCA CTT GCT CAA AAT CTG TGA C-3' & 5'- TGC CAT CCA CTG ATG TTC CAT C-3' & $B s / l$ \\
\hline rs11077 & XP05 & $A>C$ & 5'-TGC TाT GGG CAA GAA TCT GGT CAC-3' & 5'-TAA AGG GGA TGT TAG CAC TAA AGA AT -3' & Bsml \\
\hline
\end{tabular}

PCR-RFLP, polymerase chain reaction-restriction fragment length polymorphism; RAN, Ran GTPase; XP05, exportin 5.

${ }^{*}$ All of the restriction enzymes were available from New England Biolabs (Ipswich, MA, USA) and the reaction conditions recommended by the instructions were used. 
Supplementary Table 2. Comparison of genotype frequencies and AOR of DICER 6095 rs13078 A>T, DICER 9480 rs3742330 T>C, DROSHA -715 rs6877842 C>G, DROSHA 4576 rs10719 T>C, RAN 1857 rs 14035 C > T, and XPO5 4485 rs11077 A>C polymorphisms between stroke subtype and controls

\begin{tabular}{|c|c|c|c|c|c|c|c|}
\hline Genotype & $\begin{array}{l}\text { Controls } \\
(n=403)\end{array}$ & $\begin{array}{c}\text { Single SVD } \\
(n=71)\end{array}$ & AOR $(95 \% \mathrm{Cl})^{*}$ & $P$ & $\begin{array}{l}\text { Multiple SVD } \\
\qquad(\mathrm{n}=66)\end{array}$ & AOR $(95 \% \mathrm{Cl})^{*}$ & $P$ \\
\hline \multicolumn{8}{|l|}{ DICER rs13078 A>T } \\
\hline AA & $360(89.3)$ & 65 (91.5) & 1.000 (reference) & & 55 (83.3) & 1.000 (reference) & \\
\hline AT & $43(10.7)$ & $6(8.5)$ & $0.817(0.321-2.081)$ & 0.672 & $11(16.7)$ & $1.799(0.845-3.830)$ & 0.128 \\
\hline$\Pi$ & 0 & 0 & NA & & 0 & NA & \\
\hline Dominant (AA vs. AT+TT) & & & $0.817(0.32-2.081)$ & 0.672 & & $1.799(0.845-3.830)$ & 0.128 \\
\hline Recessive (AA+AT vs. T ) & & & NA & & & NA & \\
\hline \multicolumn{8}{|l|}{ DICER rs3742330 T>C } \\
\hline$\Pi$ & $148(36.7)$ & $20(28.2)$ & 1.000 (reference) & & 18 (27.3) & 1.000 (reference) & \\
\hline TC & $180(44.7)$ & $33(46.5)$ & $1.380(0.740-2.574)$ & 0.312 & $37(56.1)$ & $1.763(0.944-3.291)$ & 0.075 \\
\hline $\mathrm{CC}$ & 75 (18.6) & $18(25.4)$ & 1.796 (0.855-3.775) & 0.122 & $11(16.7)$ & $0.993(0.424-2.328)$ & 0.988 \\
\hline Dominant (T vs. TC+CC) & & & $1.490(0.831-2.671)$ & 0.181 & & $1.549(0.852-2.817)$ & 0.152 \\
\hline Recessive (T+TC vs. CC) & & & 1.429 (0.769-2.658) & 0.259 & & $0.779(0.380-1.600)$ & 0.497 \\
\hline \multicolumn{8}{|l|}{ DROSHA rs6877842 C>G } \\
\hline $\mathrm{CC}$ & $371(92.1)$ & $67(94.4)$ & 1.000 (reference) & & $64(97.0)$ & 1.000 (reference) & \\
\hline CG & $31(7.7)$ & $4(5.6)$ & $0.777(0.256-2.354)$ & 0.655 & $1(1.5)$ & $0.189(0.025-1.433)$ & 0.107 \\
\hline GG & $1(0.2)$ & 0 & NA & 0.998 & $1(1.5)$ & $8.288(0.459-149.7)$ & 0.152 \\
\hline Dominant (CC vs. $\mathrm{CG}+\mathrm{GG}$ ) & & & $0.757(0.250-2.288)$ & 0.622 & & $0.375(0.086-1.639)$ & 0.193 \\
\hline Recessive (CC+CG vs. GG) & & & NA & 0.998 & & $8.768(0.489-157.1)$ & 0.140 \\
\hline \multicolumn{8}{|l|}{ DROSHA rs10719 T>C } \\
\hline$\Pi$ & $228(56.6)$ & 34 (47.9) & 1.000 (reference) & & $37(56.1)$ & 1.000 (reference) & \\
\hline TC & $158(39.2)$ & $31(43.7)$ & $1.253(0.722-2.174)$ & 0.423 & $25(37.9)$ & 1.009 (0.572-1.782) & 0.975 \\
\hline $\mathrm{CC}$ & $17(4.2)$ & $6(8.5)$ & 1.837 (0.639-5.277) & 0.259 & $4(6.1)$ & $1.690(0.494-5.788)$ & 0.403 \\
\hline Dominant (T vs. TC+CC) & & & 1.305 (0.768-2.215) & 0.325 & & 1.061 (0.616-1.828) & 0.830 \\
\hline Recessive (T+TC vs. CC) & & & $1.596(0.568-4.483)$ & 0.375 & & $1.583(0.495-5.063)$ & 0.439 \\
\hline \multicolumn{8}{|l|}{ RAN rs $14035 \mathrm{C}>\mathrm{T}$} \\
\hline $\mathrm{CC}$ & $240(59.9)$ & $43(60.6)$ & 1.000 (reference) & & $39(59.1)$ & 1.000 (reference) & \\
\hline CT & $149(37.0)$ & $25(35.2)$ & $0.860(0.491-1.508)$ & 0.600 & $25(37.9)$ & $0.930(0.526-1.645)$ & 0.803 \\
\hline$\Pi$ & $14(3.5)$ & $3(4.2)$ & $1.081(0.257-4.541)$ & 0.915 & $2(3.0)$ & $1.053(0.222-4.998)$ & 0.948 \\
\hline Dominant (CC vs. CT+T) & & & $0.879(0.509-1.516)$ & 0.642 & & $0.939(0.540-1.634)$ & 0.824 \\
\hline Recessive (CC+CT vs. TT) & & & $1.325(0.342-5.145)$ & 0.684 & & $1.137(0.244-5.296)$ & 0.871 \\
\hline \multicolumn{8}{|l|}{ XP05 rs11077 A>C } \\
\hline AA & $319(79.2)$ & $60(84.5)$ & 1.000 (reference) & & $57(86.4)$ & 1.000 (reference) & \\
\hline $\mathrm{AC}$ & 79 (19.6) & $11(15.5)$ & $0.734(0.358-1.503)$ & 0.398 & $9(13.6)$ & $0.603(0.278-1.307)$ & 0.200 \\
\hline $\mathrm{CC}$ & $5(1.2)$ & 0 & NA & 0.998 & 0 & NA & 0.998 \\
\hline Dominant (AA vs. $A C+C C$ ) & & & $0.692(0.339-1.414)$ & 0.313 & & $0.562(0.260-1.215)$ & 0.143 \\
\hline Recessive (AA+AC vs. CC) & & & NA & 0.998 & & NA & 0.998 \\
\hline
\end{tabular}

Values are presented as number (\%).

AOR, adjusted odds ratio; RAN, Ran GTPase; XPO5, exportin 5; LAD, large artery disease; SVD, small vessel disease; Cl, confidence interval; NA, not available. *The adjusted odds ratio on the basis of risk factors, such as age, gender, hypertension, diabetes mellitus, hyperlipidemia, smoking. 


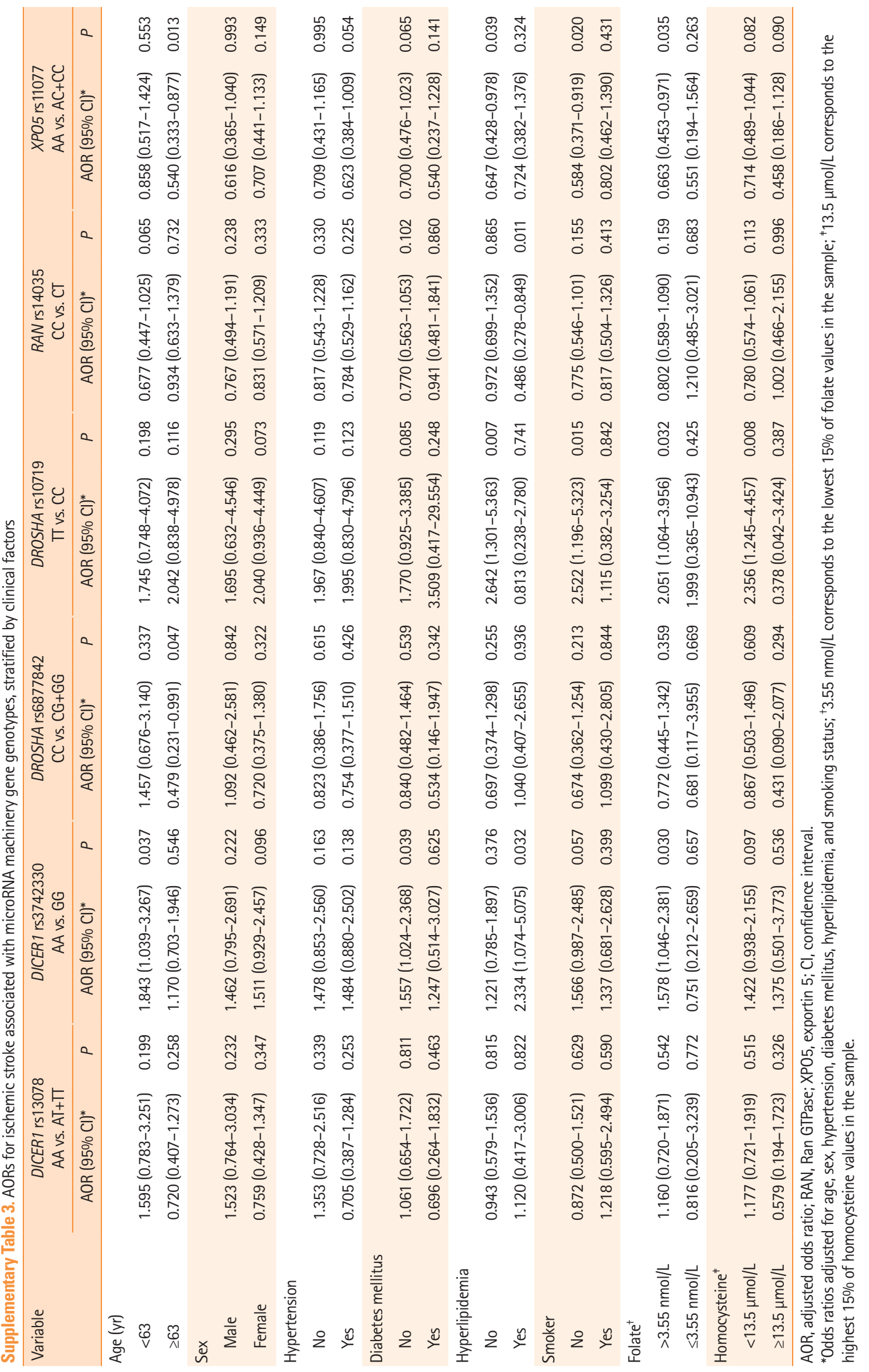


Supplementary Table 4. Adjusted odds ratios for ischemic stroke associated with DICER genotypes, combined by clinical factors

\begin{tabular}{|c|c|c|c|c|}
\hline Characteristic & DICER rs $13078 \mathrm{AA}$ & DICER rs13078 AT+TT & DICER rs3742330 AA & DICER rs3742330 GG \\
\hline \multicolumn{5}{|l|}{ Sex } \\
\hline Male & 1.000 (reference) & $1.523(0.764-3.034)$ & 1.000 (reference) & $1.462(0.795-2.691)$ \\
\hline Female & 1.151 (0.808-1.639) & $1.037(0.542-1.986)$ & 1.022 (0.562-1.859) & $2.413(1.208-4.819)$ \\
\hline \multicolumn{5}{|l|}{ Age (yr) } \\
\hline$<63$ & 1.000 (reference) & 1.657 (0.812-3.384) & 1.000 (reference) & $1.843(1.039-3.267)$ \\
\hline$\geq 63$ & $0.876(0.545-1.410)$ & $0.813(0.378-1.747)$ & $1.081(0.663-1.763)$ & $1.381(0.756-2.520)$ \\
\hline \multicolumn{5}{|l|}{ Hypertension } \\
\hline No & 1.000 (reference) & $1.353(0.728-2.516)$ & 1.000 (reference) & $1.478(0.853-2.560)$ \\
\hline Yes & 2.578 (1.933-3.439) & 1.825 (0.986-3.379) & 2.337 (1.452-3.760) & $3.418(2.028-5.762)$ \\
\hline \multicolumn{5}{|l|}{ Diabetes mellitus } \\
\hline No & 1.000 (reference) & 1.061 (0.654-1.722) & 1.000 (reference) & $1.557(1.024-2.368)$ \\
\hline Yes & $2.230(1.527-3.256)$ & $1.524(0.601-3.864)$ & $2.133(1.159-3.927)$ & $2.033(0.968-4.266)$ \\
\hline \multicolumn{5}{|l|}{ Hyperlipidemia } \\
\hline No & 1.000 (reference) & $0.943(0.579-1.536)$ & 1.000 (reference) & $1.221(0.785-1.897)$ \\
\hline Yes & 1.381 (1.003-1.901) & $1.443(0.556-3.751)$ & $1.392(0.826-2.345)$ & $3.484(1.740-6.977)$ \\
\hline \multicolumn{5}{|l|}{ Smoker } \\
\hline No & 1.000 (reference) & $0.872(0.500-1.521)$ & 1.000 (reference) & $1.566(0.987-2.485)$ \\
\hline Yes & $1.212(0.853-1.721)$ & $1.475(0.720-3.021)$ & $1.223(0.693-2.158)$ & $2.095(1.042-4.213)$ \\
\hline \multicolumn{5}{|l|}{ Folate $(\mathrm{nmol} / \mathrm{L})^{*}$} \\
\hline$>3.55$ & 1.000 (reference) & 1.160 (0.720-1.871) & 1.000 (reference) & $1.578(1.046-2.381)$ \\
\hline$\leq 3.55$ & $3.730(2.307-6.029)$ & $2.159(0.617-7.553)$ & $5.227(2.347-11.64)$ & $4.010(1.587-10.13)$ \\
\hline \multicolumn{5}{|c|}{ Homocysteine $(\mu \mathrm{mol} / \mathrm{L})^{+}$} \\
\hline$<13.5$ & 1.000 (reference) & 1.177 (0.721-1.919) & 1.000 (reference) & $1.422(0.938-2.155)$ \\
\hline$\geq 13.5$ & $1.904(1.252-2.896)$ & $1.067(0.388-2.936)$ & 1.845 (0.941-3.619) & $2.365(1.105-5.063)$ \\
\hline
\end{tabular}

${ }^{*} 3.55 \mathrm{nmol} / \mathrm{L}$ corresponds to the lowest $15 \%$ of folate values in the sample; ${ }^{+} 13.5 \mu \mathrm{mol} / \mathrm{L}$ corresponds to the highest $15 \%$ of homocysteine values in sample. 
Supplementary Table 5. Adjusted odds ratios for ischemic stroke associated with DROSHA genotypes, combined by clinical factors

\begin{tabular}{|c|c|c|c|c|}
\hline Characteristic & DROSHA rs6877842 CC & DROSHA rs6877842 CG+GG & DROSHA rs10719 Tा & DROSHA rs10719 CC \\
\hline \multicolumn{5}{|l|}{ Sex } \\
\hline Male & 1.000 (reference) & $1.092(0.462-2.581)$ & 1.000 (reference) & $1.695(0.632-4.546)$ \\
\hline Female & $1.077(0.761-1.523)$ & $0.885(0.431-1.820)$ & 1.289 (0.834-1.992) & $3.423(1.390-8.427)$ \\
\hline \multicolumn{5}{|l|}{ Age (yr) } \\
\hline$<63$ & 1.000 (reference) & $1.452(0.674-3.130)$ & 1.000 (reference) & $1.708(0.730-3.999)$ \\
\hline$\geq 63$ & $0.811(0.508-1.295)$ & $0.581(0.244-1.387)$ & $0.670(0.360-1.246)$ & $2.046(0.640-6.538)$ \\
\hline \multicolumn{5}{|l|}{ Hypertension } \\
\hline No & 1.000 (reference) & $0.823(0.386-1.756)$ & 1.000 (reference) & $1.967(0.840-4.607)$ \\
\hline Yes & $2.404(1.815-3.184)$ & $1.879(0.924-3.823)$ & $2.415(1.666-3.501)$ & $4.781(1.981-11.54)$ \\
\hline \multicolumn{5}{|l|}{ Diabetes mellitus } \\
\hline No & 1.000 (reference) & $0.840(0.482-1.464)$ & 1.000 (reference) & $1.770(0.925-3.385)$ \\
\hline Yes & $2.193(1.520-3.166)$ & $1.104(0.311-3.918)$ & 2.351 (1.449-3.814) & $12.046(1.541-94.19)$ \\
\hline \multicolumn{5}{|l|}{ Hyperlipidemia } \\
\hline No & 1.000 (reference) & $0.697(0.374-1.298)$ & 1.000 (reference) & $2.642(1.301-5.363)$ \\
\hline Yes & 1.365 (0.994-1.874) & $1.388(0.563-3.421)$ & 1.415 (0.947-2.114) & $1.240(0.401-3.832)$ \\
\hline \multicolumn{5}{|l|}{ Smoker } \\
\hline No & 1.000 (reference) & $0.674(0.362-1.254)$ & 1.000 (reference) & $2.522(1.195-5.323)$ \\
\hline Yes & $1.175(0.836-1.652)$ & $1.401(0.545-3.602)$ & $1.181(0.766-1.819)$ & $1.662(0.583-4.739)$ \\
\hline \multicolumn{5}{|l|}{ Folate $(\mathrm{nmol} / \mathrm{L})^{*}$} \\
\hline$>3.55$ & 1.000 (reference) & $0.772(0.445-1.342)$ & 1.000 (reference) & $2.051(1.064-3.956)$ \\
\hline$\leq 3.55$ & 3.401 (2.144-5.397) & $2.415(0.435-13.40)$ & $2.635(1.488-4.665)$ & $4.775(0.984-23.17)$ \\
\hline \multicolumn{5}{|c|}{ Homocysteine $(\mu \mathrm{mol} / \mathrm{L})^{+}$} \\
\hline$<13.5$ & 1.000 (reference) & $0.867(0.503-1.496)$ & 1.000 (reference) & $2.356(1.245-4.457)$ \\
\hline$\geq 13.5$ & 1.798 (1.199-2.695) & $0.830(0.198-3.475)$ & $2.020(1.186-3.441)$ & $1.289(0.211-7.870)$ \\
\hline
\end{tabular}

${ }^{*} 3.55 \mathrm{nmol} / \mathrm{L}$ corresponds to the lowest $15 \%$ of folate values in the sample; ${ }^{+} 13.5 \mu \mathrm{mol} / \mathrm{L}$ corresponds to the highest $15 \%$ of homocysteine values in sample. 
Supplementary Table 6. Adjusted odds ratios for ischemic stroke associated with RAN and XPO5 genotypes, combined by clinical factors

\begin{tabular}{|c|c|c|c|c|}
\hline Characteristic & RAN rs $14035 \mathrm{CC}$ & RAN rs 14035 CT & XPO5 rs11077 AA & XP05 rs $11077 \mathrm{AC}+\mathrm{CC}$ \\
\hline \multicolumn{5}{|l|}{ Sex } \\
\hline Male & 1.000 (reference) & $0.767(0.494-1.191)$ & 1.000 (reference) & $0.616(0.365-1.040)$ \\
\hline Female & $1.010(0.656-1.557)$ & $0.990(0.588-1.666)$ & $0.966(0.668-1.397)$ & $0.842(0.473-1.498)$ \\
\hline \multicolumn{5}{|l|}{ Age (yr) } \\
\hline$<63$ & 1.000 (reference) & $0.697(0.460-1.057)$ & 1.000 (reference) & $0.861(0.519-1.429)$ \\
\hline$\geq 63$ & $0.634(0.356-1.131)$ & $0.703(0.367-1.346)$ & 0.761 (0.464-1.249) & $0.686(0.333-1.413)$ \\
\hline \multicolumn{5}{|l|}{ Hypertension } \\
\hline No & 1.000 (reference) & $0.817(0.543-1.228)$ & 1.000 (reference) & $0.709(0.431-1.165)$ \\
\hline Yes & $2.500(1.758-3.556)$ & 1.938 (1.297-2.894) & $2.425(1.795-3.277)$ & $1.502(0.918-2.457)$ \\
\hline \multicolumn{5}{|c|}{ Diabetes mellitus } \\
\hline No & 1.000 (reference) & $0.770(0.563-1.053)$ & 1.000 (reference) & $0.698(0.476-1.023)$ \\
\hline Yes & $1.918(1.218-3.021)$ & $1.877(1.056-3.336)$ & $2.223(1.494-3.306)$ & $1.229(0.579-2.610)$ \\
\hline \multicolumn{5}{|l|}{ Hyperlipidemia } \\
\hline No & 1.000 (reference) & $0.972(0.699-1.352)$ & 1.000 (reference) & $0.647(0.428-0.978)$ \\
\hline Yes & $1.837(1.227-2.749)$ & $0.934(0.593-1.472)$ & 1.403 (0.996-1.977) & $1.027(0.575-1.836)$ \\
\hline \multicolumn{5}{|l|}{ Smoker } \\
\hline No & 1.000 (reference) & $0.775(0.546-1.101)$ & 1.000 (reference) & $0.584(0.371-0.919)$ \\
\hline Yes & $1.208(0.790-1.847)$ & 1.207 (0.727-2.002) & $1.133(0.783-1.637)$ & $1.079(0.621-1.877)$ \\
\hline \multicolumn{5}{|l|}{ Folate $(\mathrm{nmol} / \mathrm{L})^{*}$} \\
\hline$>3.55$ & 1.000 (reference) & $0.802(0.590-1.090)$ & 1.000 (reference) & $0.663(0.453-0.971)$ \\
\hline$\leq 3.55$ & $3.156(1.791-5.564)$ & $2.833(1.360-5.900)$ & $3.457(2.075-5.758)$ & $2.155(0.867-5.355)$ \\
\hline \multicolumn{5}{|c|}{ Homocysteine $(\mu \mathrm{mol} / \mathrm{L})^{+}$} \\
\hline$<13.5$ & 1.000 (reference) & $0.780(0.574-1.061)$ & 1.000 (reference) & 0.714 (0.489-1.044) \\
\hline$\geq 13.5$ & 1.450 (0.882-2.383) & 1.566 (0.827-2.969) & 1.865 (1.197-2.907) & $0.872(0.392-1.939)$ \\
\hline
\end{tabular}

RAN, Ran GTPase; XP05, exportin 5.

${ }^{*} 3.55 \mathrm{nmol} / \mathrm{L}$ corresponds to the lowest $15 \%$ of folate values in the sample; ${ }^{\dagger} 13.5 \mu \mathrm{mol} / \mathrm{L}$ corresponds to the highest $15 \%$ of homocysteine values in sample. 


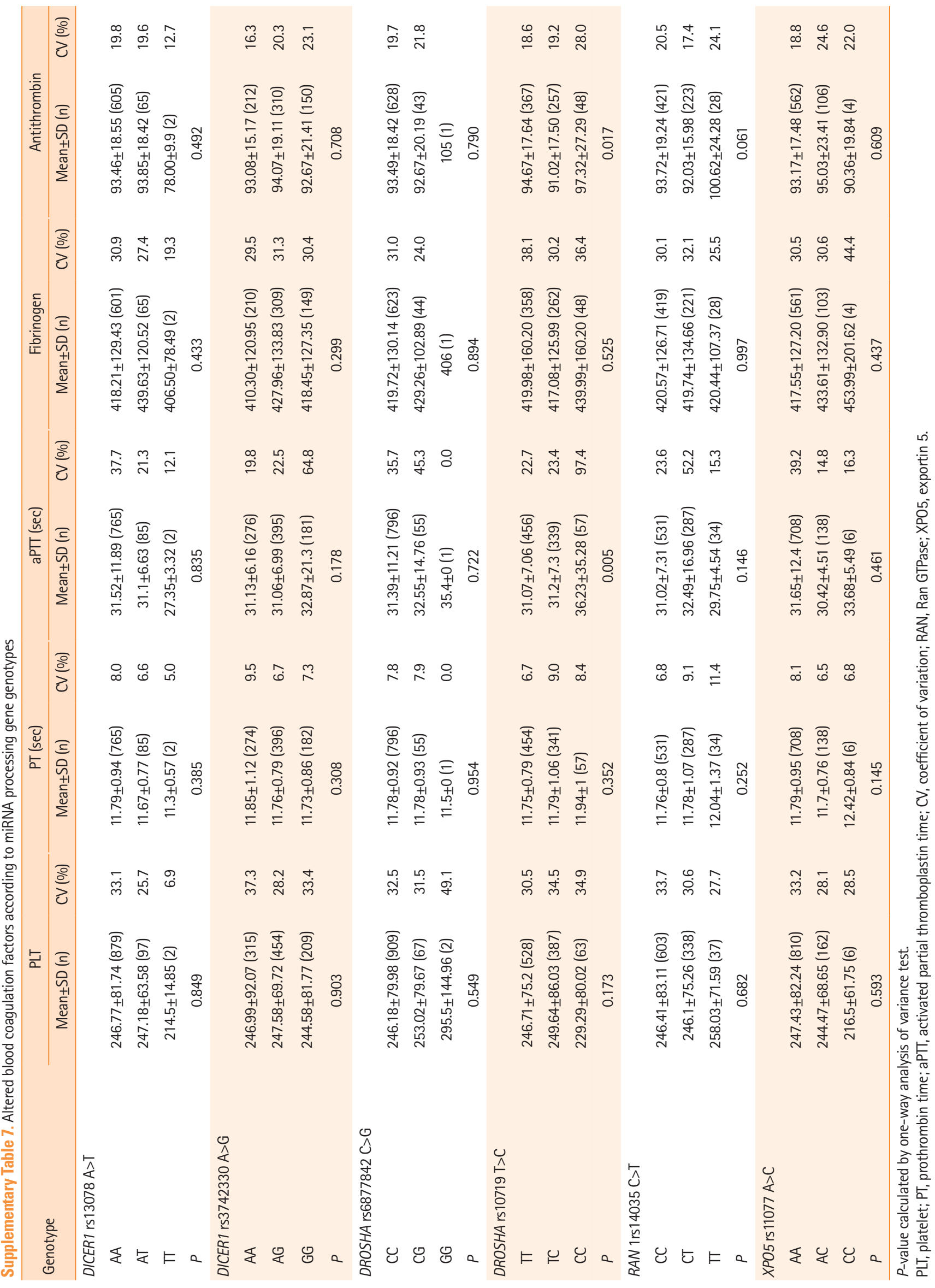




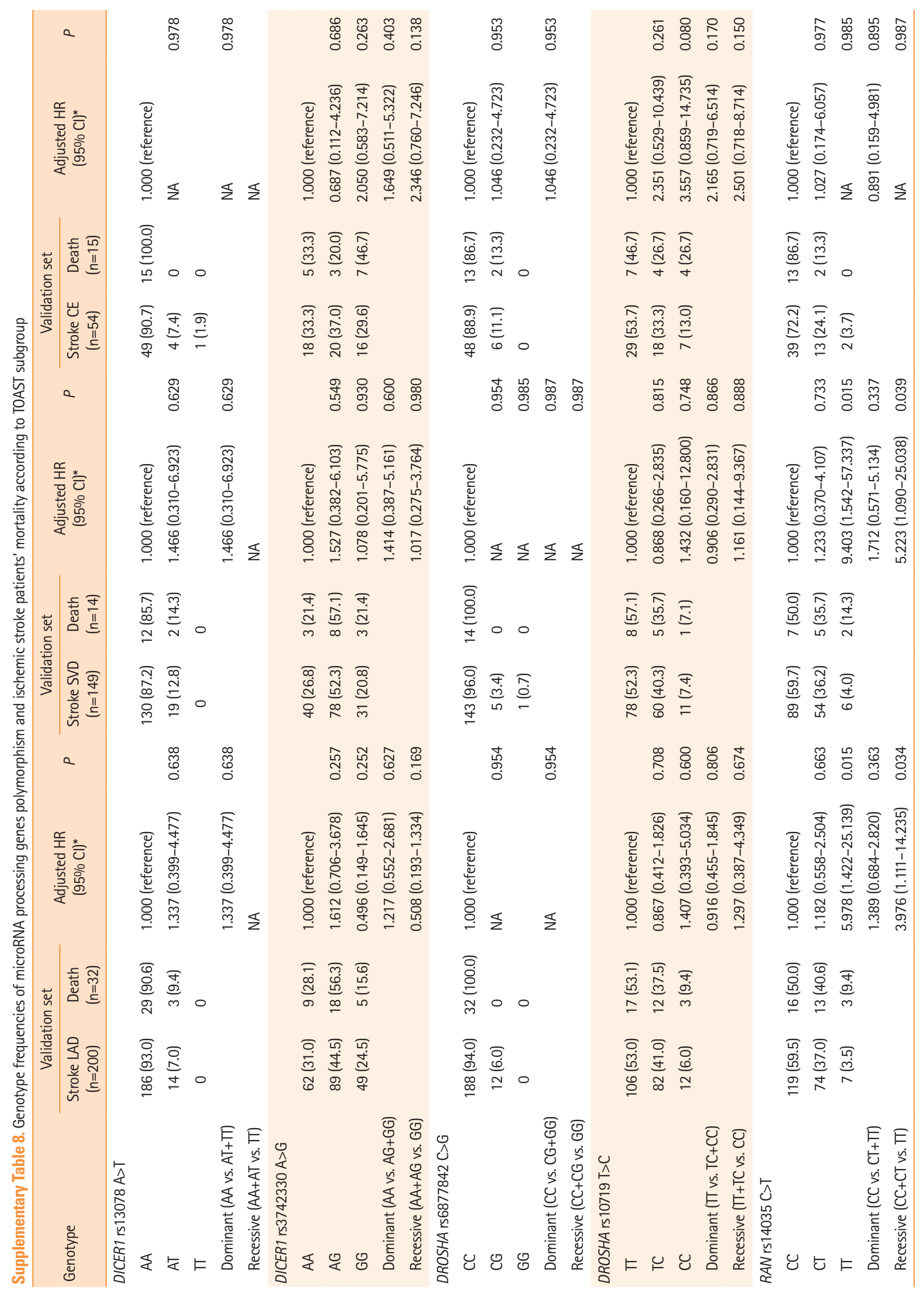




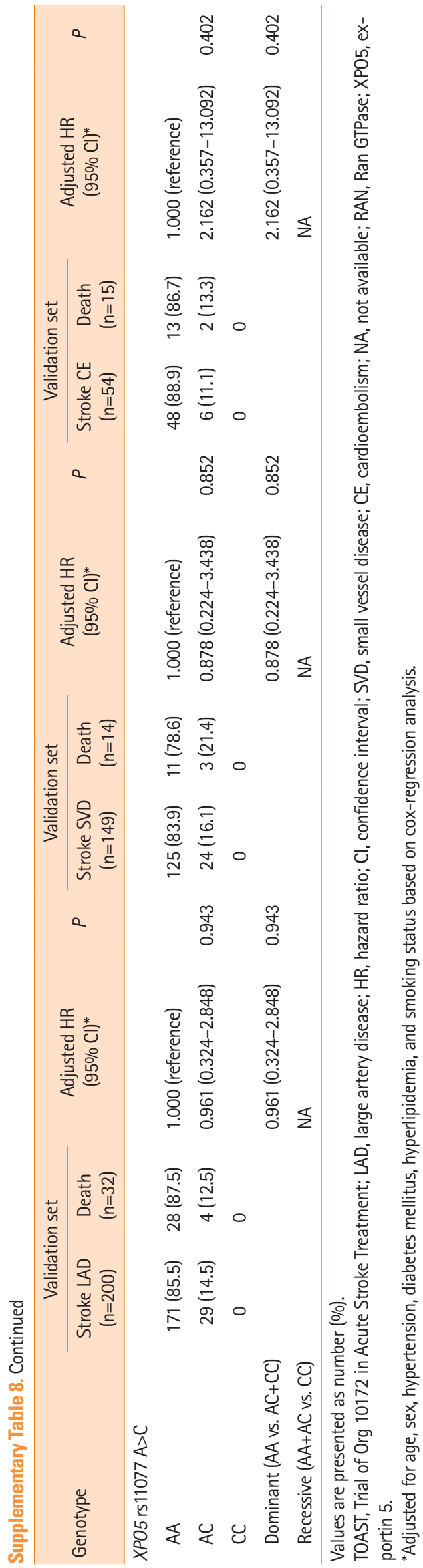


Supplementary Table 9. Results of stepwise Cox regression analysis of ischemic stroke survival

\begin{tabular}{|c|c|c|c|c|}
\hline Covariate & $\beta$ & SEM & $\mathrm{HR}(95 \% \mathrm{Cl})$ & $P^{*}$ \\
\hline \multicolumn{5}{|l|}{ RAN rs14035 CC vs. TT in LAD group } \\
\hline Age & 0.083 & 0.025 & $1.086(1.034-1.141)$ & 0.001 \\
\hline \multicolumn{5}{|c|}{ RAN rs14035 CC+CT vs. TT in LAD group } \\
\hline Age & 0.051 & 0.018 & $1.052(1.016-1.090)$ & 0.005 \\
\hline \multicolumn{5}{|l|}{ RAN rs14035 CC vs. TT in SVD group } \\
\hline Genetic variant (CC vs. TT) & 1.960 & 0.851 & $7.100(1.340-37.629)$ & 0.021 \\
\hline Age & 0.098 & 0.033 & $1.103(1.035-1.176)$ & 0.003 \\
\hline \multicolumn{5}{|c|}{ RAN rs 14035 CC+CT vs. TT in SVD group } \\
\hline Genetic variant (CC+CT vs. TT) & 1.573 & 0.769 & $4.819(1.067-21.764)$ & 0.041 \\
\hline Age & 0.057 & 0.024 & $1.058(1.010-1.110)$ & 0.020 \\
\hline
\end{tabular}

SEM, standard error of the mean; HR, hazard ratio; $C l$, confidence interval; RAN, Ran GTPase; LAD, large artery disease; SVD, small vessel disease. * P-value calculated by Cox proportional-hazards regression based on stepwise method. 
Supplementary Table 10. Frequency of DICER and DROSHA genotype combinations predicted by multidimensional reduction in ischemic stroke cases and controls

\begin{tabular}{|c|c|c|c|c|c|}
\hline Genotype & $\begin{array}{l}\text { Controls } \\
(n=403)\end{array}$ & $\begin{array}{c}\text { Case } \\
(n=585)\end{array}$ & $\operatorname{AOR}(95 \% \mathrm{Cl})^{*}$ & $P^{+}$ & $P^{\ddagger}$ \\
\hline \multicolumn{6}{|c|}{ DICER rs13078 A>T/DICER rs3742330 A>G } \\
\hline AA/AA & $123(30.5)$ & $152(26.0)$ & 1.000 (reference) & & \\
\hline $\mathrm{AA} / \mathrm{AG}$ & $165(40.9)$ & $243(41.5)$ & $1.139(0.821-1.580)$ & 0.435 & 0.435 \\
\hline$A A / G G$ & $70(17.4)$ & $132(22.6)$ & $1.351(0.911-2.002)$ & 0.134 & 0.179 \\
\hline $\mathrm{AA} / \mathrm{AG}+\mathrm{GG}$ & $237(58.8)$ & $375(64.1)$ & $1.209(0.892-1.639)$ & 0.220 & 0.251 \\
\hline AT/AA & $25(6.2)$ & $17(2.9)$ & $0.546(0.273-1.092)$ & 0.087 & 0.139 \\
\hline $\mathrm{AT} / \mathrm{AG}$ & $15(3.7)$ & $34(5.8)$ & $1.881(0.958-3.695)$ & 0.067 & 0.139 \\
\hline $\mathrm{AT} / \mathrm{AG}+\mathrm{GG}$ & $18(4.5)$ & $38(6.5)$ & $1.748(0.930-3.285)$ & 0.083 & 0.139 \\
\hline $\mathrm{AT}+\mathrm{TT} / \mathrm{AA}$ & $25(6.2)$ & $17(2.9)$ & $0.546(0.273-1.092)$ & 0.087 & 0.139 \\
\hline$A T+T / A G$ & $15(3.7)$ & $37(6.3)$ & $2.033(1.044-3.961)$ & 0.037 & 0.139 \\
\hline \multicolumn{6}{|c|}{ DROSHA rs6877842 C>T/DROSHA rs10719 T>C } \\
\hline $\mathrm{CC} / \mathrm{TT}$ & $206(51.1)$ & $281(48.0)$ & 1.000 (reference) & & \\
\hline $\mathrm{CC} / \mathrm{TC}$ & $148(36.7)$ & $221(37.8)$ & $1.083(0.812-1.445)$ & 0.587 & 0.587 \\
\hline $\mathrm{CC} / \mathrm{CC}$ & $17(4.2)$ & $46(7.9)$ & $2.005(1.093-3.678)$ & 0.025 & 0.125 \\
\hline $\mathrm{CC} / \mathrm{TC}+\mathrm{CC}$ & $165(40.9)$ & $267(45.6)$ & $1.177(0.893-1.553)$ & 0.248 & 0.587 \\
\hline $\mathrm{CG} / \mathrm{TT}$ & $21(5.2)$ & $22(3.8)$ & $0.788(0.410-1.514)$ & 0.474 & 0.587 \\
\hline $\mathrm{CG}+\mathrm{GG} / \mathrm{TT}$ & $22(5.5)$ & $23(3.9)$ & $0.787(0.415-1.491)$ & 0.462 & 0.587 \\
\hline
\end{tabular}

Values are presented as number (\%). Combinations with frequencies of less than $5 \%$ in cases and controls are not shown.

$\mathrm{AOR}$, adjusted odds ratios; $\mathrm{Cl}$, confidence interval.

${ }^{*}$ Odds ratio adjusted for age, sex, hypertension, diabetes mellitus, hyperlipidemia, and smoking status; ${ }^{\dagger} P$-value calculated by logistics regression analysis; ${ }^{\ddagger} P$ value calculated by false discovery rate test. 
Supplementary Table 11. Allele combinations of DICER, DROSHA, RAN, and XPO5 polymorphisms between ischemic stroke patients and control subjects by multidimensional reduction method

\begin{tabular}{|c|c|c|c|c|c|}
\hline Haplotype & Controls $(2 n=806)$ & Cases $(2 n=1,170)$ & $\mathrm{OR}(95 \% \mathrm{Cl})^{*}$ & $P^{+}$ & $P^{+}$ \\
\hline \multicolumn{6}{|c|}{ DICER rs13078 A >T-DICER rs3742330 A>G-DROSHA rs6877842 C>G-DROSHA rs10719 T>C-RAN rs14035 C>T-XP05 rs11077 A>C } \\
\hline A-A-C-T-C-A & $207(25.7)$ & $301(25.7)$ & 1.000 (reference) & & \\
\hline A-A-C-T-C-C & $32(4.0)$ & $23(2.0)$ & $0.645(0.368-1.129)$ & 0.157 & 0.165 \\
\hline A-A-C-T-T-C & $9(1.1)$ & $3(0.3)$ & $0.299(0.080-1.116)$ & 0.079 & 0.095 \\
\hline A-A-C-C-C-C & $9(1.1)$ & $3(0.3)$ & $0.299(0.080-1.116)$ & 0.079 & 0.095 \\
\hline A-A-C-C-T-C & 0 & $14(1.2)$ & $26.02(1.544-438.5)$ & 0.0002 & 0.001 \\
\hline A-A-G-T-C-A & $8(1.0)$ & 0 & $0.053(0.003-0.919)$ & 0.003 & 0.009 \\
\hline A-G-C-T-C-A & $184(22.8)$ & $286(24.4)$ & 1.394 (1.088-1.786) & 0.010 & 0.024 \\
\hline A-G-C-T-C-C & $21(2.6)$ & $14(1.2)$ & $0.598(0.298-1.200)$ & 0.165 & 0.165 \\
\hline A-G-C-T-T-A & $36(4.5)$ & $70(6.0)$ & $1.744(1.130-2.693)$ & 0.014 & 0.028 \\
\hline A-G-C-C-C-A & $39(4.8)$ & $86(7.4)$ & 1.978 (1.309-2.988) & 0.001 & 0.004 \\
\hline A-G-C-C-C-C & $1(0.1)$ & $18(1.5)$ & 16.15 (2.140-121.8) & 0.0002 & 0.001 \\
\hline A-G-G-T-C-A & $6(0.7)$ & $19(1.6)$ & $2.841(1.118-7.218)$ & 0.024 & 0.038 \\
\hline T-G-C-T-C-A & $2(0.2)$ & $11(0.9)$ & $4.934(1.083-22.47)$ & 0.025 & 0.038 \\
\hline \multicolumn{6}{|c|}{ DICER rs3742330 A>G-DROSHA rs6877842 C>G-DROSHA rs10719 T>C-RAN rs14035 C>T-XPO5 rs11077 A>C } \\
\hline A-C-T-C-A & $220(27.3)$ & $321(27.4)$ & 1.000 (reference) & & \\
\hline A-C-T-C-C & $34(4.2)$ & $23(2.0)$ & $0.464(0.266-0.809)$ & 0.007 & 0.011 \\
\hline A-C-T-T-A & $74(9.2)$ & $70(6.0)$ & $0.648(0.448-0.938)$ & 0.023 & 0.031 \\
\hline A-C-T-T-C & $11(1.4)$ & $3(0.3)$ & $0.187(0.052-0.678)$ & 0.006 & 0.011 \\
\hline A-C-C-T-C & 0 & $14(1.2)$ & $19.89(1.180-335.4)$ & 0.001 & 0.003 \\
\hline A-G-T-C-A & $8(1.0)$ & 0 & $0.040(0.002-0.703)$ & 0.001 & 0.003 \\
\hline G-C-T-C-C & $22(2.7)$ & $15(1.3)$ & $0.467(0.237-0.921)$ & 0.037 & 0.042 \\
\hline G-C-C-C-A & $39(4.8)$ & $88(7.5)$ & $1.546(1.022-2.340)$ & 0.043 & 0.043 \\
\hline $\mathrm{G}-\mathrm{C}-\mathrm{C}-\mathrm{C}-\mathrm{C}$ & $1(0.1)$ & $20(1.7)$ & 13.71 (1.825-102.9) & 0.0004 & 0.003 \\
\hline \multicolumn{6}{|c|}{ DICER rs3742330 A>G-DROSHA rs10719 T>C-RAN rs14035 C>T-XP05 rs11077 A>C } \\
\hline A-T-C-A & $230(28.5)$ & $323(27.6)$ & 1.000 (reference) & & \\
\hline A-T-C-C & $35(4.3)$ & $25(2.1)$ & $0.509(0.296-0.873)$ & 0.014 & 0.024 \\
\hline A-T-T-A & $77(9.6)$ & $79(6.8)$ & $0.731(0.511-1.044)$ & 0.099 & 0.099 \\
\hline A-T-T-C & $11(1.4)$ & $4(0.3)$ & $0.259(0.081-0.824)$ & 0.017 & 0.024 \\
\hline A-C-C-C & $12(1.5)$ & $4(0.3)$ & $0.237(0.076-0.746)$ & 0.010 & 0.023 \\
\hline A-C-T-C & 0 & $14(1.2)$ & $20.66(1.226-348.4)$ & 0.001 & 0.004 \\
\hline G-T-C-C & $26(3.2)$ & $17(1.5)$ & $0.466(0.247-0.878)$ & 0.024 & 0.028 \\
\hline $\mathrm{G}-\mathrm{C}-\mathrm{C}-\mathrm{C}$ & 0 & $20(1.7)$ & $29.21(1.757-485.8)$ & $<0.0001$ & 0.0001 \\
\hline \multicolumn{6}{|c|}{ DICER rs3742330 A>G-DROSHA rs10719 T>C-XP05 rs11077 A>C } \\
\hline A-T-A & $308(38.2)$ & $403(34.4)$ & 1.000 (reference) & & \\
\hline A-T-C & $44(5.5)$ & $28(2.4)$ & $0.486(0.296-0.799)$ & 0.004 & 0.010 \\
\hline G-T-A & 233 (28.9) & $390(33.3)$ & $1.279(1.027-1.594)$ & 0.029 & 0.048 \\
\hline G-T-C & $28(3.5)$ & $22(1.9)$ & $0.601(0.337-1.070)$ & 0.104 & 0.104 \\
\hline $\mathrm{G}-\mathrm{C}-\mathrm{A}$ & $65(8.1)$ & $121(10.3)$ & $1.423(1.017-1.991)$ & 0.045 & 0.056 \\
\hline $\mathrm{G}-\mathrm{C}-\mathrm{C}$ & $3(0.4)$ & $20(1.7)$ & $5.095(1.500-17.31)$ & 0.004 & 0.010 \\
\hline \multicolumn{6}{|c|}{ DICER rs3742330 A>G-XPO5 rs11077 A>C } \\
\hline$A-A$ & $418(51.9)$ & $570(48.7)$ & 1.000 (reference) & & \\
\hline $\mathrm{A}-\mathrm{C}$ & $57(7.1)$ & $48(4.1)$ & $0.618(0.412-0.925)$ & 0.022 & 0.022 \\
\hline G-A & $298(37.0)$ & $511(43.7)$ & $1.257(1.039-1.522)$ & 0.020 & 0.022 \\
\hline
\end{tabular}

Values are presented as number (\%).

RAN, Ran GTPase; XPO5, exportin 5; OR, odds ratio; $\mathrm{Cl}$, confidence interval.

${ }^{*}$ Odds ratios was calculated to reference for total frequency; ${ }^{\dagger} P$-value calculated by chi-square test; ${ }^{*} P$-value calculated by false discovery rate test. 

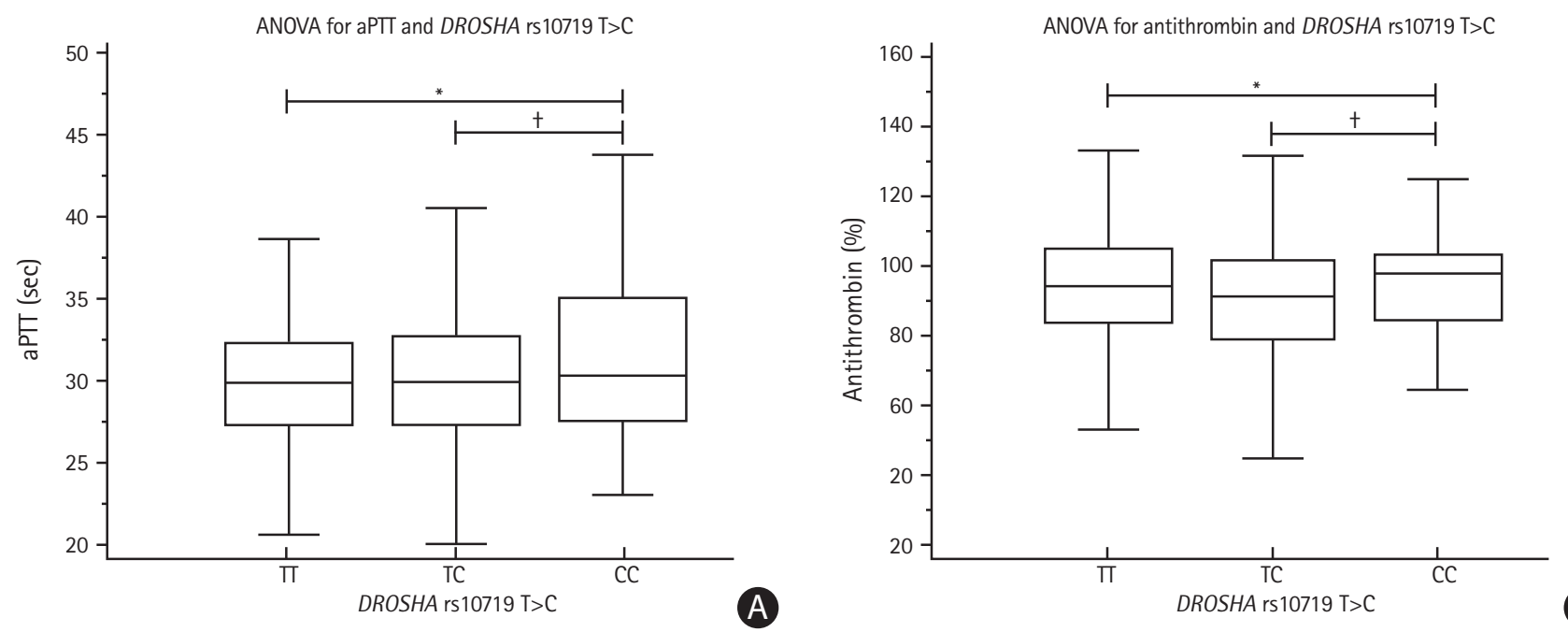

Supplementary Figure 1. Differences in activated partial thromboplastin time (aPTT) and antithrombin proportions based on DROSHA rs 10719 T>C in ischemic stroke patients. Statistical analysis was performed using analysis of variance (ANOVA) test or Student t-test for each DROSHA rs10719 T>C genotype. (A) aPTT: the blood coagulation time was significantly different $(P=0.005)$ between the DROSHA rs $10719 \Pi(31.07 \pm 7.06), \mathrm{TC}(31.20 \pm 7.30)$, and CC (36.23 \pm 35.28$)$ genotypes. (B) Plasma antithrombin proportion: it was found that the DROSHA rs10719 T>C polymorphism affected the antithrombin proportion. The DROSHA

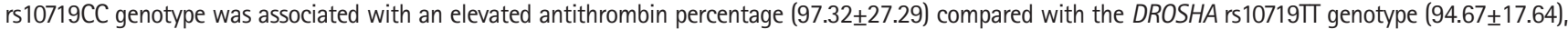
which had high antithrombin proportion relative to the DROSHA rs $10719 \mathrm{CC}$ genotype $(P=0.017) .{ }^{*} P<0.05$ calculated by ANOVA test; ${ }^{+} P<0.05$ calculated by Student t-test. 